NBER WORKING PAPER SERIES

\title{
WHEN IS CAPITAL ENOUGH TO GET FEMALE MICROENTERPRISES GROWING? EVIDENCE FROM A RANDOMIZED EXPERIMENT IN GHANA
}

\author{
Marcel Fafchamps \\ David McKenzie \\ Simon R. Quinn \\ Christopher Woodruff \\ Working Paper 17207 \\ http://www.nber.org/papers/w17207
NATIONAL BUREAU OF ECONOMIC RESEARCH
1050 Massachusetts Avenue
Cambridge, MA 02138
July 2011

We are grateful to Markus Mobius and conference and seminar participants at Auvergne, Bristol, the IPA Microfinance conference, Madrid, Michigan, Oxford, Paris, Stern (NYU), Tilburg, Leuven, the World Bank, and Microsoft Research, Cambridge for useful comments. The authors thank Caroline Kouassiaman for outstanding work as project coordinator, and Innovations for Poverty Action for their support on the ground. Financial support from the World Bank' Gender Action Plan and Research Budget is gratefully acknowledged. The views expressed herein are those of the authors and do not necessarily reflect the views of the National Bureau of Economic Research.

NBER working papers are circulated for discussion and comment purposes. They have not been peerreviewed or been subject to the review by the NBER Board of Directors that accompanies official NBER publications.

(C) 2011 by Marcel Fafchamps, David McKenzie, Simon R. Quinn, and Christopher Woodruff. All rights reserved. Short sections of text, not to exceed two paragraphs, may be quoted without explicit permission provided that full credit, including $\odot$ notice, is given to the source. 
When is capital enough to get female microenterprises growing? Evidence from a randomized experiment in Ghana

Marcel Fafchamps, David McKenzie, Simon R. Quinn, and Christopher Woodruff

NBER Working Paper No. 17207

July 2011

JEL No. O12,O16

\begin{abstract}
Standard models of investment predict that credit-constrained firms should grow rapidly when given additional capital, and that how this capital is provided should not affect decisions to invest in the business or consume the capital. We randomly gave cash and in-kind grants to male- and female-owned microenterprises in urban Ghana. Our findings cast doubt on the ability of capital alone to stimulate the growth of female microenterprises. First, while the average treatment effects of the in-kind grants are large and positive for both males and females, the gain in profits is almost zero for women with initial profits below the median, suggesting that capital alone is not enough to grow subsistence enterprises owned by women. Second, for women we strongly reject equality of the cash and in-kind grants; only in-kind grants lead to growth in business profits. The results for men also suggest a lower impact of cash, but differences between cash and in-kind grants are less robust. The difference in the effects of cash and in-kind grants is associated more with a lack of self-control than with external pressure. As a result, the manner in which funding is provided affects microenterprise growth.
\end{abstract}

\author{
Marcel Fafchamps \\ Oxford University \\ marcel.fafchamps@economics.ox.ac.uk \\ David McKenzie \\ The World Bank, MSN MC3-307 \\ 1818 H Street N.W. \\ Washington, DC 20433 \\ dmckenzie@worldbank.org
}

\author{
Simon R. Quinn \\ Oxford University \\ simon.quinn@economics.ox.ac.uk \\ Christopher Woodruff \\ Graduate School of IR/PS \\ UC, San Diego \\ 9500 Gilman Drive \\ La Jolla, CA 92093-0519 \\ and NBER \\ cwoodruff@ucsd.edu
}




\section{Introduction}

Despite the emphasis placed by microfinance organizations on lending to female business owners, evidence from three recent randomized controlled trials has cast doubt on the ability of capital alone to grow female-operated microenterprises (de Mel et al 2008, Banerjee et al 2010, and Karlan and Zinman 2010). ${ }^{1}$ The three experiments were all run in South and Southeast Asian countries: Sri Lanka, India and the Philippines. In Sri Lanka, the capital was provided as grants, while in India and the Philippines, capital was provided by increasing the availability of microloans. In Sri Lanka and the Philippines, the lack of returns in female-owned enterprises contrasted with evidence of positive returns in male-owned enterprises.

One possible interpretation is that female-owned microenterprises in these countries are already operating at their efficient level of capital, which just happens to be very low for most firms. Emran et al. (2007), for instance, argue that many of the women drawn into self-employment have low efficient scale and are only self-employed because of labor market imperfections. Labor market imperfections for women may be particularly strong in societies like those in South Asia, as evidenced by low labor force participation rates among women. This raises the question of whether capital might be more successful in growing female-owned microenterprises in other areas of the world. ${ }^{2}$ In much of Africa, for example, female labor force participation rates are higher than in Asia, and women are more integral to household income generation. It is therefore possible that the scope for female firm growth from more capital is higher in Africa.

An alternative explanation is that the small scale of many female-owned firms is in fact not efficient, but instead arises from a lack of separation between household and business decisionmaking and from inefficiencies in the way people allocate assets between them. One form of inefficiency can arise from self-control problems, leading individuals to not undertake productive investments today that have large payoffs in the future (Banerjee and Mullainathan, 2010; Duflo et al, 2010). A second form of inefficiency can come from inefficient intra-household allocation of resources (Udry, 1996; Somville, 2011) or pressure to share with others in ones social network (Charlier, 1999; Platteau, 2000; di Falco and Bulte, 2009). Either of these cases can cause a

\footnotetext{
${ }^{1}$ Bjorvatn et al. (2011) also find no effect of capital grants on either male of female small businesses in Tanzania, but their sample is restricted to non-credit constrained entrepreneurs so it is unclear how relevant these findings are for microenterpreneurs in general.

${ }^{2}$ This is related to the more general issue of external validity, a common refrain in recent debates about what the profession is learning from randomized experiments (e.g. Banerjee and Duflo, 2009; Ravallion, 2009; Deaton 2010).
} 
lack of asset integration, so that it is not only how much capital, but the form that this capital comes in, which determines the extent to which it helps grow the business.

This paper uses a randomized experiment in Ghana to test between competing models of microenterprise investment and growth and thereby better understand the conditions under which capital alone is enough for enterprise growth. The intervention itself is closely modeled on the design used by de Mel et al. (2008, 2009a) in Sri Lanka. A sample of both female and male microenterprise owners who had no paid employees at the time of the baseline survey were randomly allocated into treatment and control groups. The treatment group received grants of 150 Ghanaian cedis (approximately $\$ 120$ at the time of the baseline). As in Sri Lanka, half the grants were provided in cash and half in kind. A key difference is that the Ghanaian sample contains more than twice as many firms as in the Sri Lankan study, providing more power to distinguish the effects of providing capital in different forms.

The experiment confirms some of the findings from the Asian experiments, but adds considerable nuance to our understanding of the role of access to additional capital in determining the growth of female-owned enterprises. A one-time in-kind grant of 150 cedis is estimated to increase monthly profits by 37-39 cedis for both males and females, a large average return on this grant. However, among females, in-kind grants only lead to profit increases for the top 40 percent of businesses in terms of initial size. Women running smaller subsistence businesses, i.e., those earning $\$ 1$ per day on average, saw no gains from access to additional capital. In contrast the returns for males occur for both smaller and larger firms. ${ }^{3}$ As in Sri Lanka, capital alone does not appear to be enough to grow subsistence businesses run by women.

We find that cash grants of the same size had a significantly smaller effect, increasing profits by only 10-14 cedis on average. When the sample is split between women and men, we find that the different in treatment effect between in-kind and cash grants is significant among women but not among men. In some specifications, but not all, men show significant increases in profits following the cash grants. This result is not significant when we condition on our baseline data, however. We find that the cash grants tend to be spent on household consumption or transferred

\footnotetext{
${ }^{3}$ The high marginal returns to the capital shocks for males are consistent with non-experimental work in Ghana which has found evidence of high returns to capital for male-owned informal enterprises. Bigsten et al. (2000) find much higher returns to physical capital than human capital in African small and medium scale manufacturing firms, Udry and Anagol (2006) find returns to be at least 60 percent per year among purchasers of used auto parts in Accra, and Schündeln (2006) finds strong evidence of financing constraints among small Ghanaian firms using a structural modeling approach.
} 
out of the house, especially when given to women whose businesses were small to begin with.

The experiment allows us to test between three competing models of microenterprise investment and growth. The results are not consistent with either a standard Ramsey model or with a variation of this model that incorporates time-inconsistent preferences. To explain a large difference in outcomes between cash and in-kind grants, we need a model with a lack of asset integration where the form in which capital comes affects the extent to which it is invested in the business. We examine two possible causes of the difference between in-kind and cash grants: self-control issues caused by time-inconsistent preferences, high discount rates, or lack of ability to save; and external pressure from others to share additional resources. We find that the effect of the cash treatment is significantly more positive for individuals with the most self-control, whereas there is no evidence of treatment heterogeneity with respect to external pressure. This is consistent with the recent evidence in Spears (2009) who suggests that present-bias is a key constraint on microentrepreneurs expanding their businesses. But it contradicts results from Anderson and Baland (2002) for Kenya and Somville (2011) for Benin, whose evidence suggests that women seek to save outside the household in order to avoid contributing to household expenses, and findings by Brune et al. (2011) in Malawi, who argue that the reason for the success of a saving commitment product is the desire to escape external pressure.

The remainder of the paper is structured as follows. In Section 2 we present the conceptual framework and testing strategy. Section 3 describes the experimental design and characteristics

of our sample. Section 4 gives the basic experimental results, and explores heterogeneity by gender, treatment type, and randomization strata. Section 5 then asks what happens to the cash grants and what distinguishes the profitable from less profitable female businesses. Section 6 examines why the cash and in-kind treatments differ, and Section 7 concludes.

\section{Conceptual framework and testing strategy}

In this section we present a conceptual framework that guides our empirical analysis. The model is organized around two key assumptions which characterize the population of microenterprises we study: entrepreneurs cannot borrow and have to self finance (only 10 percent of our sample has ever had a formal loan); and they have different abilities and ability is a complement to capital. We first present a model of capital accumulation without time inconsistency and derive testable predictions regarding the effect of a capital grant. We then introduce time consistency 
and self-control issues and discuss how experimental predictions are affected. Next we discuss asset integration and intra-household issues. The testing strategy is presented at the end.

\subsection{The Ramsey model}

Consider an entrepreneur facing a standard accumulation problem of the form:

$$
\begin{gathered}
\max _{c_{t}>0, k_{t} \geq 0, w_{t} \geq 0} \sum_{t=0}^{\infty} \delta^{t} u\left(c_{t}\right) \text { subject to } \\
c_{t}=\pi\left(k_{t}, \theta\right)+r w_{t}-\left(k_{t+1}-k_{t}\right)-\left(w_{t+1}-w_{t}\right)
\end{gathered}
$$

where $k$ is capital invested in a business with total return to capital $\pi(k, \theta)$, variable $\theta$ is individual specific talent, $\delta$ is the discount factor, and $w$ is a financial asset with return $r .{ }^{4}$ We assume $\partial \pi / \partial k \geq 0$ (positive or zero returns to capital) but $\partial^{2} \pi / \partial k^{2}<0$ (decreasing returns to scale). Decreasing returns to scale may be due to the presence of fixed factors, such as entrepreneur time and family labor. We also assume that $\partial^{2} \pi / \partial k \partial \theta>0$ : more talented entrepreneurs have higher marginal returns to capital. ${ }^{5}$

There are two possible treatments: a cash transfer $M_{t}$ and an in-kind transfer $E_{t}$ at an arbitrary time $t$. Both can be turned into more capital $k$ but it takes time to liquidate grant $E_{t}$ that comes in the form of equipment or inventories. In contrast, $M_{t}$ is liquid and perfectly fungible with $k$ or $w$ or $c$. We derive model predictions about $\partial k / \partial M$ and $\partial k / \partial E$.

We first note that, by asset arbitrage, $w_{t}=0$ if $\pi_{t}^{\prime}(k, \theta)>r$. In this case, the first order conditions are as follows:

$$
\begin{aligned}
\beta^{t} u_{t}^{\prime} & =\lambda_{t} \\
\lambda_{t}\left(1+\pi_{t}^{\prime}\right) & =\lambda_{t-1}
\end{aligned}
$$

where $\pi^{\prime}$ denotes the marginal return to capital and $\lambda_{t}$ is the Lagrange multiplier associated with the constraint. From the above we get a standard Euler equation of the form:

$$
1+\pi_{t}^{\prime}(k, \theta)=\frac{1}{\delta} \cdot \frac{u_{t-1}^{\prime}}{u_{t}^{\prime}}
$$

\footnotetext{
${ }^{4}$ Variable $\pi(k, \theta)$ measures value added, that is, return to capital and family labor net of intermediate input costs and other recurrent costs. Given the nature of the studied firms, this corresponds to an accounting notion of profit, but not to an economic notion of profit/return to capital since we have not imputed the cost of the entrepreneur's labor.

${ }^{5}$ It is conceivable that a minimum level of capital is needed to initiate a business. Since all households in our sample by construction have a business, we ignore this here.
} 
If we ignore savings $w_{t}$, there exists a steady state level of capital $k^{*}$ such that profit $\pi$ and consumption $c$ are constant and:

$$
\pi^{\prime}\left(k^{*}, \theta\right)=\rho
$$

where $\rho \equiv \frac{1-\delta}{\delta}$. The proof follows from the fact that, without savings $w_{t}$, the above is a standard Ramsey model. Given that $\partial^{2} \pi / \partial k^{2}<0$ it follows that $d k^{*} / d \rho>0$ - more patient entrepreneurs have larger $k^{*}$.

If $r>\rho$, the entrepreneur stops investing in the firm once the marginal return to capital falls below $r$, and invests in $w$ instead. The optimal firm size is then given by:

$$
\pi^{\prime}\left(k^{* *}, \theta\right)=r
$$

with $k^{* *}<k^{*}$. Given our assumption that, $\partial^{2} \pi / \partial k \partial \theta>0$ comparative statics imply that both $d k^{*} / d \theta>0$ and $d k^{* *} / d \theta>0$ - more talented entrepreneurs have larger steady state capital and firm size. Only patient agents - that is, those with $\rho<r-$ ever hold non-zero savings, $w_{t}>0$.

If $k_{t}<\min \left\{k^{*}, k^{* *}\right\}$, the cash and in-kind treatments are predicted to increase capital and profits by the same amount. ${ }^{6}$ Their long term effect is to shorten the time necessary to reach the steady state firm size. In contrast, when a entrepreneur has reached $k^{*}$ or $k^{* *}$, the effect of the two treatments is different. If $k=k^{* *}$, a cash transfer has no effect on capital and $\partial k_{t+s} / \partial M_{t}$ $=0$ for any $s \geq 0$; it raises consumption $c$ and savings $w$ instead. In this case we should observe no cash treatment effect on profits $\pi_{t+s}(k, \theta)$ : the cash treatment $M_{t}$ should not be invested in firms that have already reached their optimal size; it should be saved instead. If the in-kind treatment $E_{t}$ cannot be liquidated immediately, however, we expect a temporary positive effect on profit: $\pi(k+E, \theta)>\pi(k, \theta)$ since, by assumption, $\partial \pi / \partial k \geq 0$. But this effect should be short-lived: the firm should return to its steady state capital level as soon as $E$ can be divested. If $k=k^{*}$ with $\rho>r$, then instead of saving in asset $w$ in order to smooth consumption of the capital grant, it is optimal for the entrepreneur to use a temporary investment in the firm as buffer to smooth consumption. In this case, $M_{t}$ and $E_{t}$ have a similar short-run effect on capital and profits.

In all cases the model predicts that the cash and in-kind treatments will result in higher consumption. In the steady state case with $\rho>r$, the household is impatient and the treatment will be consumed rapidly before consumption returns to its steady state level. In the case where

\footnotetext{
${ }^{6}$ In the interest of space, we do not discuss the case where $k_{t}+M>\min \left\{k^{*}, k^{* *}\right\}>k_{t}$. This case is effectively a weighted average of the two cases we describe.
} 
$r>\rho$, there will be more smoothing, that is, part of the treatment will be saved and consumed later. In the case where $k_{t}$ is below its steady state, we expect an increase in consumption out of higher profits.

\subsection{Time-inconsistent preferences}

We now introduce quasi-hyperbolic preferences as in Laibson (1997). At time $t$ the household sets $k_{t}$ so as to solve:

$$
\max _{\left\{c_{s}, w_{s}, k_{s}\right\}} u\left(c_{t}\right)+\beta \sum_{s=t+1}^{\infty} \delta^{s} u\left(c_{s}\right) \text { subject to (1) }
$$

where $\beta<1$. But once at time $t+1$, the household sets $k_{t+1}$ according to:

$$
\max _{\left\{c_{s+1}, w_{s+1}, k_{s+1}\right\}} u\left(c_{t+1}\right)+\beta \sum_{s=t+2}^{\infty} \delta^{s} u\left(c_{s}\right) \text { subject to (1). }
$$

This means that at time $t+1$ the household wants to revisit decisions taken at time $t$ and set paths for $\left\{c_{t+1}, c_{t+2}, \ldots w_{t+1}, w_{t+2}, \ldots, k_{t+1}, k_{t+2}, \ldots\right\}$ that differ from those set in period $t$.

In Appendix 1 we show that the entrepreneur stops investing after reaching a steady state level of capital $k^{s}$ (for a sophisticate) or $k^{m}$ (for a myopic decision maker) which are, in general, smaller than $k^{*}$. Model predictions regarding the effect of a capital grant are similar to the Ramsey model. If the firm has already reached its steady state $k^{s}$ or $k^{m}$, the cash transfer $M$ will be rapidly consumed while the in-kind grant $E$ will be divested as quickly as is feasible. If $k_{t}<k^{s}$ or $k^{m}$, then the additional cash $M$ or inventories $E$ will remain in the business and increase future profits.

To summarize, the standard and time inconsistent models both predict that the long-term effect of the cash and in-kind transfers on capital and profit are nil for firms that have already reached their steady state capital level. The short-term effect of the cash transfer on capital and profit is also nil. For the in-kind treatment there is a short-term increase in capital and profit until the household is able to divest, which is expected to happen as soon as is feasible. In contrast, for firms that are below steady state, both cash and in-kind transfers are predicted to be entirely invested and the effect of the grant is to reduce the time taken to reach the optimal firm size.

\subsection{Asset non-integration and family pressure}

In the experiment most in-kind grants are used to purchase inventories and raw materials rather than machinery (and firm owners could chose which of these it was). It should therefore be 
relatively easy to de-capitalize these grants (by selling and not replacing stock) and take them out of the business. This differs from the conditionality on school attendance or vaccination in traditional conditional cash transfers, which are not reversible. We should therefore think of the difference between cash and in-kind treatments as earmarking the grant for a specific purpose and reducing its liquidity. Given that inventory turnover is quite rapid in the kind of enterprises covered by this study - e.g., one week - the reduction in liquidity is minimal. Based on the models discussed so far, we should therefore expect little difference between cash and in-kind treatments.

Until now we have assumed that people make decisions regarding asset accumulation in an integrated manner, i.e., that consumption $c$, profits $\pi$, capital $k$ and savings $w$ are regarded as fungible. Yet experimental evidence suggests that asset integration often fails. For instance, it is common for experimental participants to exhibit considerable risk aversion even though the stakes are very small stakes relative to their wealth (Harrison, Lau and Rutstrom 2007; Andersen, Harrison, Lau and Rutstrom 2008). Similarly, Camerer, Babcock, Loewenstein and Thaler (1997) find that cab drivers make labor supply decisions based on single-day earnings. In other words, they fail to integrate earnings over a longer time period of a week or a month when making enterprise decisions.

Self-control issues arising from dynamic inconsistencies in preferences are one reason people may not undertake productive activities today that have large payoffs in the future. For example, Duflo et al. (2010) find farmers in Kenya fail to undertake profitable investments in fertilizer due to present-bias, but that offering small time-limited discounts can induce them to do so. Banerjee and Mullainathan (2010) show that these time-inconsistency issues can be particularly important for the poor. Given this, in-kind grants may then act as a "nudge" to get firm owners to invest in their business, and once the money is in inventories and equipment, limited illiquidity may help the firm owner avoid impulse purchases.

Asset integration may also fail for reasons external to the individual, such as disagreement over the allocation of resources between household or family members. If intra-household bargaining is efficient, asset integration should hold. But if binding commitment is not possible, for instance because of lack of trust, intra-household allocation of resources can be inefficient. Udry (1996), for instance, shows that organic fertilizer is not allocated efficiently between male and female fields in Burkina Faso. Anderson and Baland (2002) similarly show that women in urban Kenya join rotating savings and credit associations (ROSCAs) to shelter money away from 
their spouse. A similar result is reported by Somville (2011) for Benin. de Mel et al. (2009a) suggest women may inefficiently over-invest in less liquid forms of business assets in order to resist spousal pressure.

Pressure to redistribute resources can also be exerted from outside the household. Platteau (2000) introduces the idea of sharing norms to economics from anthropology. He notes that in many developing countries, especially in sub-Saharan Africa, individuals often live in large households and have strong links to extended family and kinship networks. Social sharing norms can make it hard for individuals to save and invest, as they are forced to share additional resources with others. These sharing norms can vary according to the source of income and how it is stored. For example, Duflo and Udry (2004) find evidence that the proceeds of different crops are used for different purposes in Côte d'Ivoire, and note that income from some crops is expected to be shared within the household and income from others is not. Charlier (1999), based on work in Côte d'Ivoire, notes that as a result of sharing norms, individuals may develop an illiquidity preference in order to be able to resist social claims without appearing selfish. Suggestive evidence supporting this view comes from di Falco and Bulte (2009), who show in South Africa that households with more kinship links spend less of their income on liquid and sharable assets, and from Baland, Guirkinger and Mali (2007), who find individuals in Cameroon taking loans even though they have high savings balances, which their interviews reveal to be a way of resisting demands for financial assistance by others. Jakiela and Ozier (2011) find in a lab experiment in rural Kenya that women invest less when the income they earn is observable to relatives, even when this reduces their expected total earnings. However, Grimm et al. (2010) offer a more mixed picture, finding in seven West-African countries that local social networks within the city actually have a positive association with business performance, whereas there is a negative association between business performance and a smaller distance to the village of origin.

In our context the existence of a "social solidarity tax", either from other household members or from extended family members, may lead to less of the cash grant being invested in the business than is the case with the in-kind grant. This could arise either due to the difference in liquidity (it takes some time to decapitalize inventories and raw materials and this time is sufficient to resist pressure for on-the-spot transfers) or to the difference in form and function (there could be an expectation to share cash coming into the household, but not to share the value of additional materials going into the business). 
To capture these ideas, let us rewrite the law of motion of entrepreneurial capital as:

$$
k_{t+1}=k_{t}+\pi\left(k_{t}, \theta\right)-h_{t}
$$

where $h_{t} \equiv c_{t}+w_{t+1}-(1+r) w_{t}$ represents what is taken out of the enterprise either to be consumed or to be invested in other assets. In the Ramsey and time inconsistent models hereafter RTI models - the optimal choices of consumption $c_{t}$ and savings $w_{t+1}$ depend on total cash-in-hand $k_{t}+\pi\left(k_{t}, \theta\right)+(1+r) w_{t}$. Unless $k_{t}$ is illiquid, increasing $k_{t}$ or $\pi_{t}$ has the same effect on cash-in-hand and thus on $h_{t}, k_{t+1}$ and $\pi_{t+1}$. In the more general case, $h_{t}=h\left(\pi_{t}, k_{t}\right)$ and asset integration requires that $h\left(\pi_{t}, k_{t}\right)=h\left(\pi_{t}+k_{t}\right)$. If households regard $k_{t}$ and $\pi_{t}$ as not fungible, they are imperfect substitutes in $h\left(k_{t}, \pi_{t}\right)$ and $h\left(\pi_{t}, k_{t}\right) \neq h\left(\pi_{t}+k_{t}\right)$. This simple observation forms the basis for our testing strategy.

As discussed earlier, asset integration may fail because assets $k_{t}$ are less susceptible to internal pressure than profits $\pi_{t}$. Turning working capital into inventories or equipment may serve as self-commitment device against the temptation of impulse purchases. This is akin to consumers putting money on a low-yield savings account that is less conveniently accessible. In the same vein, Fafchamps, Udry, and Czukas (1998) present evidence suggesting that, in times of duress, farming households prefer to reduce consumption than sell animals because the latter would translate into lower income in the future.

The other possibility is that pressure from household members and other relatives works as a tax on the business with $\frac{\partial h}{\partial \pi}>\frac{\partial h}{\partial k} \geq 0$. Money tied up in inventories or equipment is less liquid and thus partly insulated from external pressure. If successful, this tactic would yield a marginal tax rate on cash flow $\frac{\partial h}{\partial \pi}$ that is higher than the marginal tax on capital $\frac{\partial h}{\partial k}$. If asset non-integration signals an effort to escape taxation of this kind, it is more likely to be observed among enterprises operated by more subordinate household members, such as married women.

When asset integration fails, cash and in-kind treatments can have systematically different effects: the in-kind transfer may be treated as adding to the firm's capital, while the cash treatment is regarded as part of the firm's cash flow, or as never having entered the firm in the first place. To illustrate, consider the simple case where $\frac{\partial h}{\partial k}=0$ but $\frac{\partial h}{\partial \pi}>0$. A steady state firm 
size $k^{v}$ is defined as a capital stock that satisfies: ${ }^{7}$

$$
\pi\left(k^{v}, \theta\right)=h\left(\pi\left(k^{v}, \theta\right)\right) .
$$

To fix ideas, suppose that $h_{t}=a \pi_{t}+b$ with $0<a<1$. The law of motion of capital becomes:

$$
k_{t+1}=k_{t}+(1-a) \pi\left(k_{t}, \theta\right)-b
$$

which resembles a Solow model with a negative drift term $b$. Provided that the marginal return to capital is high enough at low values of $k,{ }^{8}$ difference equation (5) has two equilibria: a high, stable equilibrium $k_{\text {high }}^{v}$ similar to the steady state of a Solow model; and an low, unstable equilibrium $k_{\text {low }}^{v}$ below which the firm closes down. For $k$ such that $k_{\text {low }}^{v}<k_{t}<k_{\text {high }}^{v}$, the firm is growing. For $k<k_{\text {low }}^{v}$, the firm is unstable and eventually disappears - and is thus unlikely to be part of our sample.

We now introduce cash and in-kind grants. Equation (5) is rewritten:

$$
k_{t+1}=k_{t}+E_{t}+(1-a)\left(\pi\left(k_{t}, \theta\right)+M_{t}\right)-b
$$

which implies that for initial values of $k$ such that $k_{\text {low }}^{v}<k_{t}<k_{\text {high }}^{v}$, the in-kind treatment $E_{t}$ has a one-for-one effect on capital stock $k_{t+1}$ but the cash treatment only has a $1-a$ effect on $k_{t+1}$ :

$$
\frac{d \Delta k_{t}}{d E_{t}}=1>1-a=\frac{d \Delta k_{t}}{d M_{t}}
$$

where the notation $\Delta k_{t}$ denotes $k_{t+1}-k_{t}$. In other words the cash treatment is predicted to have a lower effect on future capital - and hence profits - than the in-kind treatment as long as $a>0$, that is, as long as $\frac{\partial h}{\partial \pi}>0$.

Turning to long-term predictions, if the firm was below its equilibrium size $k_{h i g h}^{v}$, the in-kind treatment speeds up convergence to the steady state $k_{h i g h}^{v}$. Future additional profits generated by $k_{t}+E_{t}$ are subject to taxation and raise future consumption. If the firm was at - or above - equilibrium size $k_{h i g h}^{v}$, then decreasing returns in capital imply $\pi\left(k_{t}, \theta\right)-h_{t}<0$ and the firm should slowly decapitalize the in-kind treatment $E_{t}$. In the special case where $h(\pi)=b$ and initial capital $k_{t}<k_{\text {low }}^{v}$ but $k_{t}+E_{t}+(1-a) \pi\left(k_{t}, \theta\right)-b>k^{v}$, the in-kind treatment pushes

\footnotetext{
${ }^{7}$ For some functions $h(\pi)$, the steady state is not stable. For instance, if $h(\pi)=b$ with $b$ a positive constant, the steady state $k^{v}$ is given by $\pi\left(k^{v}, \theta\right)=b$, but the firm eventually closes down if $k_{t}<k^{v}$ while it expands forever for $k_{t}>k^{v}$. In contrast, if $h(\pi)=\pi$, the law of motion of capital becomes $k_{t+1}=k_{t}$ and any capital level $k$ is an equilibrium.

${ }^{8} \mathrm{~A}$ standard Inada condition.
} 
the firm above the minimal threshold size and ensures its long term survival. ${ }^{9}$ In the special case where $h(\pi)=\pi$, the in-kind treatment pushes the firm to a new equilibrium level of capital $k_{t}+E_{t}$ : future profits increase but there is no further addition or subtraction to capital after $t+1$.

The above example can be generalized to allow $h_{t}$ to depend on both $\pi_{t}$ and $k_{t}$. For instance, let $h_{t}=a \pi_{t}+\eta k_{t}+b$ with and $0<\eta<1$. The no-closure stable steady state $k^{w}$ is the (highest) value of $k$ that solves: $:^{10}$

$$
(1-a) \pi\left(k^{w}, \theta\right)-b=\eta k^{w}
$$

It follows that equilibrium firm size is a decreasing function of both $a$ and $\eta$. The in-kind treatment has a $1-\eta$ effect on $k_{t+1}$ while the cash treatment has a $1-a$, also less-than-onefor-one, effect on $k_{t+1}$. Asset integration requires that $a=\eta$. If investing in inventories and equipment is successful as protecting the capital of the enterprise, we should observe $a>\eta$. This forms the basis of our testing strategy.

\subsection{Testing strategy}

We estimate models of the form:

$$
\begin{aligned}
& \pi_{i, t+s}=\beta_{1} M_{i t}+\beta_{2} E_{i t}+u_{i, t+s} \\
& k_{i, t+s}=\alpha_{1} M_{i t}+\alpha_{2} E_{i t}+v_{i, t+s}
\end{aligned}
$$

where $t$ is the time of treatment, $\pi_{i, t+s}$ is the profit of entrepreneur $i$ at time $t+s$ after treatment, $k_{i, t+s}$ is the capital stock, and $u_{i, t+s}$ and $v_{i, t+s}$ are error terms. Coefficients $\alpha$ 's and $\beta$ 's are the average effects of each of the two treatments on capital stock and profits, respectively, across the population of firms in our sample.

The RTI models predict $\alpha_{1}=\alpha_{2}>0$ and $\beta_{1}=\beta_{2}>0$ if the firm was below its steady state at the time of the treatment. They also predict $\alpha_{1}=\beta_{1}=0$ if the firm had already reached its equilibrium size at time $t$ such that $k_{t}=k^{* *}, k^{m}$, or $k^{s}$. Because the in-kind treatment is not immediately fungible, these models also predict $\alpha_{2}>0$ and $\beta_{2}>0$ for a small time from

\footnotetext{
${ }^{9}$ In this case, the treatment eliminates a poverty trap.

${ }^{10}$ If $b=0$, this is a Solow model in disguise. If we set $\pi(k, \theta)=k^{\lambda} e^{\theta}$, the steady state is the usual:

$$
k^{w}=\left[\frac{1-a}{\eta} e^{\theta}\right]^{\frac{1}{1-\lambda}}
$$
}

where $1-a$ is the savings rate and $\eta$ plays the role of depreciation. 
treatment $s$, but eventually $\alpha_{2}=\beta_{2}=0$ for $s$ large enough, as $k$ returns to its steady state from above. A similar result obtains if $k_{t}=k^{*}$ and firm capital is used as buffer to smooth consumption.

In contrast, the model without asset integration makes predictions that do not in general depend on whether the firm is above or below steady state $k_{h i g h}^{v}$. Predictions however depends on the form taken by the external pressure function $h($.$) . If h_{t}$ is a constant lumpsum $b$ with $a=\eta=0$, then both treatments $M_{t}$ and $E_{t}$ increase capital one for one, that is, $\alpha_{1}=\alpha_{2}=1$ at time $s=t+1$, that is, one period after treatment. If, in contrast, $h_{t}=\pi_{t}$ and $M_{t}$ is regarded as part of the firm's cash flow $\pi_{t}$ but $E_{t}$ is not, then $\alpha_{1}=0$ and $\alpha_{2}=1$ at all $s \geq t+1$.

For the intermediate case where $h_{t}=a \pi_{t}+b$ with $a<1$, the model predicts that $E_{t}$ has a one-for-one effect on capital stock $k_{t+1}$, that is, that $\alpha_{2}=1$ but $M_{t}$ only has a $1-a$ effect on $k_{t+1}$, i.e., $0<\alpha_{1}=1-a<1$. The larger $a$ is, the closer $\alpha_{1}$ is to 0 . Finally, when $h_{t}=a \pi_{t}+\eta k_{t}+b$, that is, when external pressure also puts a tax on capital, then $0<\alpha_{2}=1-\eta<1$ while we still have $0<\alpha_{1}=1-a<1$. Asset integration requires that $\alpha_{1}=\alpha_{2}$ and hence that $\beta_{1}=\beta_{2}$.

We have discussed two main reasons why household asset integration may fail: internal pressure driven by self-commitment problems; and external pressure from household and family members. If external pressure comes primarily from husbands, unmarried women should show a lower $a$ and $\eta$ and thus a stronger response to treatment. If pressure comes from children or the extended family, a stronger response to treatment will be observed for entrepreneurs without children or with a smaller extended family. To implement this idea, let $a=a_{0}+a_{1} z$ and $\eta=\eta_{0}+\eta_{1} z$ with $z$ a vector of proxies for different kinds of external pressure. We estimate a model of the form:

$$
\begin{aligned}
\pi_{i, t+s} & =(1-a) M_{i t}+(1-\eta) E_{i t}+v_{i, t+s} \\
& =\left(1-a_{0}\right) M_{i t}-a_{1} M_{i t} z_{i}+\left(1-\eta_{0}\right) E_{i t}-\eta_{1} E_{i t} z_{i}+v_{i, t+s}
\end{aligned}
$$

If a specific element of $z_{i}$ is associated with a higher implicit tax rate on cash flow, then the coefficient of $M_{i t} z_{i}$ should be negative and significant. Similarly, if it is associated with higher taxation of capital, the coefficient of $E_{i t} z_{i}$ should be negative and significant.

We test internal pressure using a similar approach. In this case, pressure comes from the non-business minded self, that is, the self susceptible to immediate gratification. In this context, keeping excess liquidity in less fungible inventories and equipment can be seen as a way to insulate working capital from temptation. If this strategy is successful, we should observe that 
$\eta_{1}<a_{1}$ for individuals with more self-commitment problems proxied by $z_{i}$.

\section{The Experiment}

\subsection{The Sample}

We purposively chose urban Ghana as the setting for this study. The choice of Ghana was motivated by the desire to provide evidence in an African context, in a country known for a history of involvement of women in business which provides a setting that is conducive to female business success. Women in Ghana have similar labor force participation rates to men, and are more likely to be self-employed. Evidence of this is seen in data from the 2000 Ghanaian Census: the labor-force participation rates for 15-60 year olds are 69.6 percent for females and 73.9 percent for males, and in urban areas 45 percent of females are non-agricultural own-account workers, compared to 33 percent of males. This contrasts sharply with Sri Lanka, the setting for the experiment in de Mel et al. (2009a), where only 7.8 percent of prime age females are self-employed, compared to 29.7 percent of prime age males.

Within Ghana we chose Accra, the capital and largest city, and the nearby industrial city of Tema. A sample of microenterprises (which we term the Ghana Microenterprise Survey) was then constructed as follows. First, enumeration areas (EAs) were selected with probability proportional to the number of households in these EAs according to the 2000 census. We randomly selected 70 EAs in Accra and 30 in Tema. Then, to reduce the costs of listing, we subdivided EAs into equal areas, such that each area would contain approximately 70 to 80 households. This typically required dividing an EA into half or thirds. One of these areas was then randomly selected from each EA. Enumerators went door to door in this area to carry out a screening survey of each household. Households were screened to identify those with an individual age 20 to 55 who was self-employed and working 30 or more hours per week in a business with no paid employees and no motorized vehicle. These criteria were used to select full-time microenterprise owners who were not so large that the grants in our experiment would have little effect.

The gender and business sector of all individuals passing this screen were then recorded. This resulted in screening 7,567 households to identify 3,907 individuals who passed the screen. Only 19.4 percent of these individuals were male, confirming the predominance of women among small enterprise owners in urban Ghana. Based on the gender mix of self-employed in these 
industries in the 2000 Census, we classified business sectors into male-dominated industries, identified as construction, repair services, manufacturing, and shoe making and repair; femaledominated industries, identified as hair and beauty care, and food and restaurant sales; and mixed industries, identified as trade and retail, and sewing and tailoring. These industries cover the vast majority of the industries in which the self-employed work in Ghana. The 4.6 percent of those screened who worked in other industries such as communication services, pharmacy, photography, fishing, and agriculture were not included in the sample.

Our aim was then to arrive at a sample of roughly 900 baseline firms stratified by gender and sector. In order to minimize the spillovers from the treatments to be carried out, we limited the sample from each EA to no more than 5 males in male-dominated and 5 males in mixed industries, and no more than 3 females in female-dominated and 3 females in mixed industries. We also ensured that only one individual was chosen from any given household. This resulted in an initial sample of 907 firms, consisting of 538 females and 369 males. A baseline survey of these firms was conducted in October and November 2008. The firm owners were asked for details of both their firm and their household.

A second pre-treatment survey of these firms was conducted in February 2009. The purpose of a second pre-treatment round was to eliminate firms most likely to attrit. In particular, 55 of the initial 907 firms could not be found on at least three attempts, 15 firm owners refused this second round, 24 firm owners were no longer operating a business, and 20 firms that did not provide details on their firm profits, expenses and sales were eliminated. This left a final sample for the experiment of 793 firms, comprising 479 females (248 in female-dominated industries and 231 in mixed industries) and 314 males (146 in male-dominated industries and 168 in mixed industries).

\subsection{Experimental design}

The design of the experiment closely followed that used in Sri Lanka by de Mel et al. (2008, 2009a). Firms which completed the first two survey rounds were randomly allocated into three groups: a control group of 396 firms, a treatment group of 198 firms which would receive 150 Ghanaian cedis (approximately US $\$ 120$ at the time of the baseline) in cash which they could use for any purpose, and a treatment group of 198 firms which would receive 150 cedis in equipment, materials, or inventories for their business. In the case of the in-kind treatment, the equipment or materials were selected by the firm owner and purchased directly by our research assistants 
with the owner.

The majority of this was in the form of inventories to sell (e.g. beauty care products, electronic goods, alcohol, food) and raw materials (e.g. wood, sandpaper, cloth, oil and other cooking ingredients, shampoos and supplies for beauty salon use). Only 24 percent of those receiving the in-kind treatment elected to buy physical equipment, with the most common equipment purchased being sewing and knitting machines by tailors, hair dryers by owners of beauty salons, and drills and other carpentry equipment by firms in woodwork. Males were more likely to get some equipment with this treatment than females (33 percent versus 19 percent). With the cash treatments, firm owners were notified by phone, or in-person, and then received the cash through money transfer at a local bank or in-person.

We also randomly selected when firms would receive their grant, staggering the timing of the grants, so that 198 firms were assigned to receive the grants after the second round, a further 181 firms assigned to receive the grants after the third round, and 18 firms were assigned to receive the grants after the fourth round. This staggering was done both for the purpose of managing the logistics of making these grants, and to provide incentives for firms to remain in the study for multiple rounds since they were told more grants would be given out after rounds 3 and 4 . These grants were framed to firms as prizes to thank firms for participating in the survey. Participants in the survey were told that we were undertaking a study of small firms in Ghana, and that some of the firms would be randomly chosen to receive prizes as a token of our appreciation for their participation in the survey. Firms which were selected in either treatment group were not told they had been selected for a prize until the time their prize was being given out.

Randomization was done via computer after the second round of data was collected. Firms were first stratified into 16 strata on the basis of gender and sector (males in male dominated industries, males in mixed industries, females in female-dominated industries, and females in mixed industries); baseline capital stock (above or below the raw baseline median of 181 cedis in capital stock); and on a binary variable called "high capture". In the second survey round, firm owners were asked on a 5 point Likert scale (ranging from $1=$ strongly disagree to $5=$ strongly agree) to assess how strongly they agreed or disagreed with the statements "Whenever I have money on hand, my spouse or other family members always end up requesting some of it", and "People who do well in their business here are likely to receive additional requests from family and friends for money to help out with some expense or another". We summed the responses 
to these two questions, and classified as "high capture" firm owners with scores of the median of 8 or above - that is if on average they agree with both statements.

Then within each strata, we ranked firms according to January 2009 reported profits (collected in the second round survey), and formed matched quadruplets of firms. We used wave 2 rather than baseline profits for the match since 9 percent of the firms did not report round 1 profits. Within the quadruplet one firm was then randomly chosen to receive the cash treatment, one to receive the in-kind treatment, and two to be control firms. We then randomly selected which quadruplets would receive their treatments after each round. In the end this resulted in the 793 firms being matched into 195 groups, of which 4 groups ranged in size from 5 to 8 firms and the remainder were quadruplets.

This randomization design was based on the analysis in Bruhn and McKenzie (2009) who showed the potential for significant increases in power and baseline balance from matched pairs (with a single treatment group) and stratification compared to simple randomization. The variables used for stratification were motivated by the results in de Mel et al. (2009a). In particular, we stratified by gender and industry since the ex post heterogeneity analysis in that paper found strong differences by gender, and some suggestion of differences according to whether women were working in female-dominated versus mixed industries. The choice of "high capture" as a stratifying variable is motivated by the literature referenced earlier that has suggested that many individuals who succeed in raising their incomes face large demands to share it from others. In addition, there was some evidence in Sri Lanka that a reason for the low returns to women is pressure from household members to redistribute resources. Stratification on baseline capital stock was done both because this was believed to be a variable which would be correlated with future profits, and to allow for testing potential heterogeneity in treatment effects for smaller and larger microenterprises. Matching of quadruplets on profits was done to achieve greater balance on the pre-treatment value of the main outcome of interest as well as to investigate treatment heterogeneity in this dimension. It also enables us to eliminate quadruplets with outlier values of pre-treatment profits and still be assured of balance and random allocation to treatments and control among the remaining sample.

\subsection{Data collection and description of firms}

The two pre-treatment survey rounds were followed up by four additional survey waves in May 2009, August 2009, November 2009, and February 2010. Of the 793 firms which completed the 
first two rounds, 730 answered the final wave survey. Appendix 1 details wave by wave attrition rates and shows the robustness of our main treatment effects to corrections for attrition.

Each follow-up round collected data on changes over the quarter in fixed capital from purchases, sales or repair; the current value of inventories and raw materials, and the value of the last month's expenses, sales, and profits. The most important firm outcome variable measured is firm profits. Profits were elicited via a direct question, following the recommendations of de Mel et al. (2009b). Firm owners were asked: "After paying all expenses, what was the income of the business (the profits) during January 2009? (Consider all expenses, including wages of employees but not including any income you paid yourself as an expense)". This definition of profit thus includes the return to the entrepreneur's labor and managerial talent. Nominal profits were converted to October 2008 real profits using the Greater Accra region Consumer Price Index collected by the Ghana Statistical Service.

An innovation in this experiment was the use of computerized cross-sectional and panel consistency checks. Data was collected using PDAs, and a consistency check was triggered whenever reported profits exceeded reported sales in the cross-section, whenever a firm reported sales but not profits, and whenever the change in profits from one quarter to the next was less than -33.3 percent or greater than +50 percent (provided the absolute change in profits was at least 20 cedis). We discuss these consistency checks in more detail in Fafchamps et al. (2010), where we show that they lead to some improvements in data quality. We therefore use the profits which incorporate the consistency checks in this paper. Nonetheless, our results are similar when we use the raw profit data.

Table 1 summarizes the basic characteristics of firms and their owners in our experimental sample, and compares the pre-treatment characteristics of firms in the control group to those assigned to either treatment group. The top of the table shows balance for the characteristics used for stratification or matching, while the remaining rows compare the characteristics of other variables of interest. Mean (median) monthly profits in January 2009 were 130 (68) cedis, and mean (median) capital stock at the same point in time was 452 (172) cedis. The grants of 150 cedis were therefore approximately equivalent to two months' profits and almost equal to the size of existing capital stock for the median firm. However, since we did not explicitly cap profits or capital stock when selecting firms into the experimental sample, there are a small number of firms with much higher levels - the maximum profit reported in our pre-treatment waves is over 5000 cedis per month. The inclusion of these few larger firms does not have much effect our 
basic results, but has a larger effect on our analysis of treatment heterogeneity. As discussed below, we therefore focus most of our analysis involving heterogeneity of treatment response on the firms in quadruplets which have baseline profits of 1500 cedis per month or less. Since randomization occurred within quadruplets, balance on baseline characteristics is achieved for this subsample also.

Table 1 shows that overall the two treatment groups look similar to the control group in terms of pre-treatment characteristics. The exceptions are October/November 2008 profits and January 2009 sales, which show significant differences across treatment groups in the trimmed sample, and differences in magnitude, if not statistical significance, in the full sample. Recall the matched randomization used the wave 2 profits. However, the correlation between wave 1 and wave 2 profits is only 0.19 , compared to a correlation of 0.58 between wave 2 and wave 3 profits, and of 0.72 for the control group between waves 5 and 6 (which is the same seasonality as between waves 1 and 2). This difference in baseline profits is due to pure chance, and is in a variable which the data suggests involves considerable noise and perhaps learning on the part of survey respondents as well. Imbalance on this baseline profit measure is thus unlikely to imply imbalance on follow-up profits, particularly given the pre-treatment balance on wave 2 profits (Bruhn and McKenzie, 2009). Nevertheless, we will show our results are largely robust to the use of firm fixed effects which account for any baseline imbalances, the main difference being in the cash-treatment for males, which we discuss in detail later.

As seen in Table 1, the mean owner in our sample is 36 years old, has almost 9 years of schooling, and has been running the firm for 7 years. The mean number of digits recalled in a Digitspan recall test is 5.1, which is almost one digit lower than the 5.9 average among Sri Lankan microenterprise owners (de Mel et al, 2008). The majority of firms are run out of the home, with 83 percent of women and 69 percent of men operating a business from their dwelling. Most firms are informal, with only 14 percent registered for taxes, and only 10 percent have ever had a loan from a bank or microfinance institution. Half of the firm owners use a susu collector, with this more common among women (58 percent) than men (34 percent). A susu collector is an informal mobile banker, who typically collects a savings deposit daily from individuals and returns them at the end of the month after subtracting one day's deposit as a fee. That is, saving is at negative interest rates in exchange for safekeeping. Besley (1995, p. 2150) states that "a frequently heard rationale for the existence of this institution is that there are difficulties for those who have a stock of liquid assets in resisting the claims of their friends and relatives 
(or even spouses)".

\section{Testing the predictive power of the models}

Before investigating the effect of the randomized capital grants on sample firms, we briefly examine the baseline data for evidence consistent with predictions made by the models presented in Section 2. The evidence we offer is non-experimental, but since we are not trying to draw causal inference, observational data remains useful.

The Ramsey model predicts, other things being equal, that more patient entrepreneurs have a higher steady state capital stock. More talented entrepreneurs should also have larger firms and thus larger capital stock. The time inconsistency model further predicts that entrepreneurs that are more hyperbolic in their discounting should also have a lower steady state capital stock.

We investigate these predictions using the baseline capital stock of all respondents. The results are shown on Table 2. Consistent with the predictions of the model, we find some evidence that more able entrepreneurs have larger capital stocks. The regression in column 1 shows that years of schooling, results from a Raven test of non-verbal reasoning, and results from a forward digitspan test all have positive measured effects, though only the digitspan score is statistically significant.

The column 1 regression also includes measures of the owner's short-term discount rate and an indication of hyperbolic attitudes. Hyperbolicity is proxied by answers to questions asked in the baseline survey involving discount rates over the two different time horizons, and patience is measured by whether a respondent has a discount rate above or below the sample median. Firm owners were asked hypothetical questions to elicit the amounts that would leave them indifferent between an amount today, and 100 cedis in one month; and between an amount in five months and 100 cedis in six months. From this we construct two proxies: an indicator variable of whether the respondent has a discount rate above the median for the one month versus today comparison (the median person would take 90 today instead of 100 in one month); and an indicator of being a hyperbolic discounter based on comparison of discount rates over the two horizons (28 percent of the sample are classified as hyperbolic). We find that hyperbolic discounters have significantly smaller businesses, consistent with the theory. Those with below median one month discount rates have insignificantly larger businesses.

Our surveys include two additional measures which each measures of self-control and the 
ability to save cash, both of which were measured pre-treatment. These refer to actual saving behavior as reported by respondents before treatment. The first is whether the respondent used a susu collector; the second, whether the respondent agrees or strongly agrees with the statement "I save regularly" (which two-thirds of respondents do). We use the principal component of these and the two discount rate measures to create an index measuring a lack of self-control. The regression in column 2 uses the index of self control in place of the discount rate measures. Those with less self control have lower baseline capital stocks.

The models also predict that individuals who are more patient and less hyperbolic should save more and grow their business faster as long as they are they below their optimal size. Conditional on the log of baseline capital, we do find that the growth in capital stock between wave 1 and 2 (i.e., before treatment) is faster for respondents who are more patient and are not hyperbolic. All these results tally with the predictions of the RTI models.

Finally, in column 3 we include a dummy for high pressure to share within the household. This variable plays in principle no role in the RTI models, but we find that this is also associated with significantly smaller capital stock at baseline. This is consistent with the idea to pressure to share affects firm size, and suggests that factors other than those in the basic RTI framework may have important effects on firm size.

All three regressions include controls for the age of the owner, and the education level of the owner's mother and father. The models also predict that, other things being equal, older entrepreneurs are likely to have larger firms because they have had more time to accumulate and learn, and thus reach their long-term steady state. The data support this. Parental education is added as a control variable for initial household wealth and socioeconomic status. The regressions also include an indicator that the owners is female. We find that female-owned businesses are significantly smaller in terms of baseline capital stock.

In sum, the regressions on Table 2 suggest that baseline capital stocks are consistent with several of the predictions made by the RTI model. The significance of pressure to share with others in the household suggests that factors outside the RTI framework may also be important. We now turn to the experimental data to investigate whether exogenous shocks to household capital are invested in ways which are consistent with model predictions. 


\section{Estimation of Experimental Treatment Effects}

Only 9 firm owners assigned to receive a grant (2\% of those assigned to treatment) did not receive one. One of these firm owners had died, three women refused the grant saying their husbands would not let them accept it, and the other five firms had attrited from the survey and could not be located to give them the grant. Given this, we focus on intent-to-treat effects, which show the impact of being randomly assigned to receive the grant - in practice there is little difference between the intent-to-treat effect and the treatment on the treated effect of actually receiving the grant given that compliance is almost $100 \%$.

\subsection{Impact on Profits by Grant Type and Gender}

Figures 1 and 2 graphically show the main results of the experiment by displaying the empirical cumulative distribution functions (CDFs) of real profits by gender and treatment group for the final two rounds of the survey. For males, Figure 1 shows that both the in-kind and cash treatments have distributions to the right of the control distribution, with separation over most of the range of profits. The in-kind and cash treatments have similar distributions up to about the 80th percentile, and then separate with the distribution of profits for the in-kind treatment lying to the right of the cash treatment profits distribution. In contrast, the distribution of real profits by treatment group for females shows two noticeable differences from that of males. First, the distribution of the cash treatment group lies right on top of that of the control group, suggesting no impact of the cash treatment on profits. Second, while the in-kind distribution lies to the right of the other two groups, this separation only occurs at about the 50th or 60th percentile. That is, for women, the in-kind treatment seems to have had an effect only for the top half of the distribution.

We then estimate the average impact of the cash and in-kind grants on firm profits. We begin by pooling together male and female business owners, and running an OLS regression of the form:

$$
\pi_{i, t+s}=\beta_{1} M_{i t}+\beta_{2} E_{i t}+\sum_{t} \delta_{t} D_{i t}+\sum_{g=1}^{G} \gamma_{g} S_{i g}+\varepsilon_{i, t+s}
$$

where $M_{i t}$ and $E_{i t}$ are dummy variables indicating whether firm $i$ has been assigned to receive either the cash or in-kind treatment by time $t$. The error term $u_{i t}$ has been decomposed into wave fixed effects $D_{i t}$, quadruplet fixed effects $S_{i g}$, and a residual $\varepsilon_{i t}$. The $G$ quadruplets are the strata used in the randomization of the two treatments across entrepreneurs (see Section 
3.2) and are included following the recommendation of Bruhn and McKenzie (2009).

We test whether either treatment is significantly different from zero. We also test the equality of effects of the two treatments $\beta_{1}=\beta_{2}$. We estimate equation (9) for the full sample, and then for the sub-sample which trims out matched quadruplets which have a firm with pre-treatment profits above 1500 cedis. ${ }^{11}$ In addition to OLS estimation conditional on group dummies, we also estimate equation (1) via individual fixed effects. The inclusion of fixed effects controls for any time invariant small-sample differences between treatment groups, such as the difference in baseline profits seen in Table 1. We cluster errors at the firm level in all specifications.

The first four columns of Table 3 show the treatment effects for the pooled sample. All four specifications show a large positive impact of the in-kind treatment on firm profits. Monthly firm profits are estimated to be 31-43 cedis higher as a result of the 150 cedis in-kind treatment. The cash treatment is significant at the 10 percent level in the untrimmed OLS specification, but becomes insignificant when trimming or using fixed effects. The coefficients are always much smaller than for the in-kind treatment, and we can reject equality of cash and in-kind grants at the 5 percent significant level for three out of four specifications and at the 10 percent level for the other. That is, cash grants have less impact on business profits than in-kind grants.

These initial results pool together all waves of the survey, thereby giving the average impact of the treatments over the observed time period and improving power (McKenzie, 2011). We observe firms at quarterly intervals, up to 12 months after treatment. Appendix 2 tests robustness to allowing the impact of the grants to vary with the time since treatment, and tests for equality of treatment effects. There is some suggestion that the impact of the in-kind treatments are greater 9-12 months after treatment than immediately afterwards, but we reject equality of treatment effects over time at the $10 \%$ level only for the in-kind treatment for females, and then only with a fixed effects specification. Given the sample sizes we have and lack of strong evidence to reject pooling, we therefore continue to pool all waves for the remainder of the paper.

In the remainder of Table 3 we allow the impact of the grants to vary by gender. Recall the randomization was stratified by gender. We modify equation (9) to allow both the treatment

\footnotetext{
${ }^{11}$ Only 7 firms have pre-treatment profits above this level, but this trimming involves dropping 28 firms (1\% of the sample) since we need to drop other firms in the matched quadruplet. Doing this ensures that balanced randomization occurred within the trimmed sample, and prevents a few firms with scale well above the rest of the sample exerting undue influence on the results.
} 
and wave effects to vary by gender:

$$
\begin{aligned}
\pi_{i, t+s} & =\beta_{1} F_{i} M_{i t}+\beta_{2} F_{i} E_{i t}+\beta_{3}\left(1-F_{i}\right) M_{i t}+\beta_{4}\left(1-F_{i}\right) E_{i t} \\
& +\sum_{t} \delta_{t} D_{i t}+\sum_{t} \delta_{t}^{F} F_{i} D_{i t}+\sum_{g=1}^{G} \gamma_{g} S_{i g}+\varepsilon_{i, t+s}
\end{aligned}
$$

where $F_{i}=1$ if entrepreneur $i$ is female, and 0 otherwise. Recall the randomization was stratified by gender.

Columns 5 and 6 estimate equation (10) by OLS with quadruplet dummies, and columns 7 and 8 with individual fixed effects. Finally, columns (9) and (10) restrict the OLS estimation to the last two waves of data. This corresponds to the data in Figures 1 and $2 .{ }^{12}$

For women, the estimated treatment effect of the cash grant is always small ( 5 cedis or less) and statistically insignificant, whereas the treatment effect of the in-kind grant is large (35-50 cedis) and statistically significant. In all specifications we can reject equality of the cash and in-kind treatment effects. This confirms what is seen visually in Figure 2, that only the in-kind grants have a significant effect for women. For males, the in-kind treatment effect is also large, although more sensitive to specification, ranging in size from 28 to 60 cedis, and statistically significant in all but one specification. After trimming, the magnitude of the in-kind treatment effect for males is very similar to that for females, and we cannot reject equality of in-kind treatment effects by gender in any specification. In contrast to females, we can never reject equality of cash and in-kind treatment effects for males. This is consistent with a failure of asset integration for females but not for males.

The cash treatment effect for males is statistically significant and large when we restrict analysis to waves 5 and 6 , which is consistent with the effects seen in Figure 1. However, using all waves of the data, the estimated impact varies between 5 and 29 cedis depending on specification, with large standard errors. The impact of cash is larger using OLS than fixed effects because of an imbalance in baseline profits for males. The group assigned to the cash grant has higher wave 1 profits (despite the same wave 2 pre-treatment profits) than either the control group or the group assigned to the in-kind treatment. Because we balanced on wave 2 profits in the randomization, the imbalance is due to chance. It is therefore not clear whether or

\footnotetext{
${ }^{12}$ Readers may be concerned that profits are artificially high in the quarter immediately after the equipment treatment if firms receiving inventories to sell count this as pure profit. But Appendix 2 shows that, if anything, the treatment effect is rising with time since treatment. Furthermore, the treatment effects are still present when focusing on these final rounds which are six months or more removed from almost all the treatments.
} 
not one should control for this pre-treatment difference. If we are prepared to treat this chance imbalance as noise and not condition on it, then there is some evidence for a significant cash effect, at least in the last two rounds. But the confidence interval for the male cash treatment effect when we do control for it with fixed effects is $(-26.5,+36.7)$, indicating that the data really have no information about the cash treatment effect for males when we condition on this difference. In contrast, the in-kind treatment effect for males and the cash and in-kind treatment effects for females are much more robust to the choice of specification, giving us more confidence in the results for these groups.

These findings contrast with earlier experiments which failed to reject the equality of cash and in-kind treatment effects in grants to microenterprises in Sri Lanka and Mexico (de Mel et al, 2008; McKenzie and Woodruff, 2008). Why?

We first note that the sample sizes used in the experiments in Sri Lanka and Mexico ultimately resulted in low power to distinguish between cash and in-kind grants. In Sri Lanka the sample size for analysis in de Mel et al. (2008) is 385 firms. They find an ITT return of 4.17 percent for the in-kind treatment, and of 6.70 percent for the cash treatment. However, the standard errors on these estimates are 2.6-2.8 percent, and one cannot reject at the 10 percent level that the in-kind treatment has twice the effect of the cash treatment $(p=0.102)$. The sample size in Mexico for the analysis by McKenzie and Woodruff (2008) is even smaller, with 113 firms after trimming. The ITT returns are 34.4 percent for cash and 16.1 percent for in-kind, but with standard errors of 23-24 percent. Thus it may be that Ghana is not different, but rather that the prior studies did not have sufficient sample to detect differences between cash and in-kind grants. We return to this issue below.

\subsection{Treatment Heterogeneity by Randomization Strata}

Next we examine treatment effect heterogeneity according to the other variables used for stratification and matching. We do this separately by gender, given the differences observed above. Let $A$ and $B$ denote the two categories of a binary variable used for stratification (e.g. $A_{i}=1$ if $i$ works in a single-sex dominated industry, and $B_{i}=1$ if $i$ works in a mixed-gender industry). 
Then we estimate separately for each gender:

$$
\begin{aligned}
\pi_{i, t+s}= & \beta_{1} A_{i} M_{i t}+\beta_{2} A_{i} E_{i t}+\beta_{3} B_{i} M_{i t}+\beta_{4} B_{i} E_{i t} \\
& +\sum_{t=2}^{6} \delta_{t} D_{i t}+\sum_{t=2}^{6} \delta_{t} B_{i} D_{i t}+\sum_{g=1}^{G} \gamma_{g} S_{i g}+\varepsilon_{i, t+s} .
\end{aligned}
$$

The results are shown in Table 4 . The top two rows of the table show the categories $A$ and $B$ which define strata. Columns (1) and (2) show the OLS and fixed effects estimates of treatment heterogeneity by the gender mix of the industry firms work in. De Mel et al. (2009a) found some evidence in Sri Lanka that the impact of grants was less for women in female-dominated industries than those in mixed industries. In Ghana, panel A of column (2) shows that with fixed effects, the cash treatment has a -6.9 cedis effect in female-dominated industries versus a 1.8 cedis effect in mixed industries, and the in-kind treatment has a 25.4 cedis effect in female-dominated industries compared to a 39.8 cedis effect in mixed industries. The point estimates are therefore consistent with the idea that the grants may have more effect on the businesses of women who operate in mixed industries. However, the differences in treatment effects by industry category are not statistically significant. Likewise panel B shows no significant heterogeneity by industry category for men.

Columns (3) and (4) examine heterogeneity according to the baseline measure of capture. Recall that individuals in the "high capture" category state that whenever they have money on hand their family members are likely to request some of it, and that people who do well in business get requests from others for help. We do not obtain significant heterogeneity according to this variable for either men or women, with large standard errors and the point estimates varying quite a lot between the OLS and fixed effects specifications. Later in the paper we examine alternative measures of capture to see whether this lack of significance is due to the particular choice of measure being used.

Finally we look at heterogeneity according to the initial size of the firm. Columns (5) and (6) consider this in terms of the initial capital stock of the firm, as firms were stratified as being above or below median baseline capital stock, while columns (7) and (8) define initial size in terms of initial profits. Since wave 2 profits was matched to form quadruplets, we first calculate the maximum wave 2 profit within a quadruplet or group, and then define firms as being in a low profits group if the maximum wave 2 profits for the group is less than 138 cedis (the median of profits over the whole sample). This classifies 62 percent of females and 45 percent of males as being in the low profits group. The results confirm the visual impression in Figures 1 and 2 . 
In particular, we see that the cash grants have no significant impact for any size female firm, while the in-kind grants only have an impact for the 40 percent or so of firms with higher initial profits or higher initial capital stock. The impact of the in-kind grants is extremely large for these female firms - monthly profits increase by 77 to 96 cedis per month for the female firms in high initial profits quadruplets, compared to an insignificant 2 to 5 cedis per month for the low profits female firms. This difference is statistically significant. In contrast, there is no such pattern for male-owned firms - the point estimates for the lower profits firms are typically just as large as those for the higher profits firms, and the difference is not statistically significant.

Taking these results together, it appears that cash grants are not increasing profits for female-owned firms, and the in-kind grants only increase profits for female-owned firms which were larger in size to begin with. The in-kind treatments also increased profits for male-owned firms, and the effect of the cash grants is inconclusive for males. There does not appear to be the same heterogeneity by initial firm size in terms of male responsiveness to the grants. This suggests that female-owned firms are better able to resist internal or external pressure when the treatment comes in the form of inventories or equipment, while the difference in treatment is less relevant for male-owned businesses. We now scrutinize this interpretation more in detail.

\section{Interpretation of the results}

\subsection{Where do the grants go?}

Table 5 examines the extent to which the grants are being used to increase the capital stock of the firm, to make transfers to non-household members, and for household spending. In panel A we show the results of estimating equation (2) with different outcomes, while in panel B we show the results of estimating equation (3) for the female sample and the categorization of low and high initial profits groups, since this is where we found large differences in treatment effects. For reasons of space we report the fixed effects estimates only (with the exception of transfers out which were not measured pre-treatment), but note when the OLS results show large differences.

We begin by looking at the impact of the grants on the capital stock of the firms. Column (1) shows this for total capital stock. In order to reduce the influence of large outliers, column (2) truncates capital stock at the 99.5th percentile, which is 6130 cedis. Both specifications suggest that capital stock is increasing by more for the in-kind treatments than for the cash treatments, both for men and women. However, the capital stock data is noisy and the standard errors 
are large, meaning we cannot reject equality of the effect of cash and in-kind grants on capital stock. Panel B shows stark differences between the women whose profits were initially low and those who had higher initial profits - there are large increases in capital stock for the high initial profits group, and no increase in capital stock for the low initial profits group that received the cash treatment. After truncating outliers, we can reject equality in treatment effects for the low and high initial profits groups for both cash and in-kind grants.

Figures 3 and 4 show the empirical CDFs of the post-treatment capital stock distribution by treatment group and gender for the final two waves of the survey. For males, Figure 3 shows a similar pattern to that of profits - namely that the distribution of the in-kind treatment group is shifted to the right compared to that of the control group across the distribution. The cash distribution is in between, although right at the top of the distribution crosses the control distribution curve several times, which explains the sensitivity of the cash treatment effect to where we truncate the data. For females, Figure 4 shows that both treatment groups overlap with the control group for the bottom 60 percent of the distribution, a pattern similar to that seen for profits. The in-kind grant distribution then separates from the control above this, with women in the in-kind treatment group having higher 70,80, and 90th percentiles of their capital stock distributions than the control group. The cash treatment group lies in between, and, unlike in the case of profits, does separate somewhat from the control group at the top of the distribution, suggesting some increases in capital for some firms as a result of the cash treatment.

Next we examine where the grants are going if not into the business. Beginning in wave 4, firm owners were asked "During the past three months, did you make any payments in cash or goods to people living outside your household?" and if so, the value of such transfers. Columns 3 and 4 show that women who received the cash grant were more likely to have made such a transfer, and to have given more. On average they are estimated to have given 8 cedis more a quarter over the last 3 quarters of the survey. This does not account for any transfers out made in the first quarter after treatment by firms treated after wave 2 , since the wave 3 survey did not collect transfers data. However, restricting the analysis to the control group and firms treated after wave 3 only marginally increases the coefficient on the cash treatment, raising it to 8.9 cedis.

The remaining columns report the estimated impacts on household expenditure, which was 
collected each wave. ${ }^{13}$ Point estimates suggest higher positive impacts on expenditure for those receiving the cash treatments than those getting the in-kind treatment or the control group, especially for women with low initial profits. We see a large and highly significant effect of the cash treatment on total quarterly spending for women as a whole, and for the subgroup of women with low initial profits. The coefficients are huge: women who were given a 150 cedis cash grant are estimated to be spending 120 cedis more a quarter after the grant. The magnitude of this coefficient appears to be driven by a few firm owners reporting very large spending levels - truncating at the 99th percentile of total expenditure lowers this coefficient to 95, and at the 95th percentile lowers it to 76 cedis (which is still significant at the $5 \%$ level). For males receiving the cash treatment, the point estimates also suggest large increases in total quarterly spending (with a coefficient of 50 to 73 cedis depending on the level of truncation), but the standard error is so large that we can never reject equality with zero.

These results therefore offer an explanation at a basic level for the profits results. More of the in-kind grants ended up in the business than the cash grants. Women, especially those with lower initial profits, appear to have spent most, if not all, of the grants on household expenditure and transfers to non-household members. As a result, we see more impact of in-kind grants than cash grants on business profits. Note however that for women with high initial profit who received the cash treatment, Table 5 shows an increase in capital stock and no significant change in spending, despite the lack of a significant increase in profits for this group. There are only 44 women who are in the high initial profits group who received the cash treatment, so small sample noise is a potential explanation. Indeed, the $95 \%$ confidence interval for the effect on profits of the cash treatment for the initial high profit group is $(-26,+40)$. So despite the small and insignificant

\footnotetext{
${ }^{13}$ Households were asked to recall the last week's expenditure on food, last month's expenditure on 9 categories (housing, fuel and light, non-durable households goods, communication, recreation, transport, household services, personal care services, and contributions to associations) and last three month's expenditure on a further 9 categories (clothing, footwear, ceremonies such as funerals and weddings, electronic goods, household furnishings, household appliances, vehicles, health expenses, and education expenses). We aggregate several categories to report estimates of impact on several categories of interest, as well as impacts on total quarterly spending (which adds 13 times weekly food, and 3 times the last month's expenses to the three month expenses). Unlike profits, panel consistency checks were not programmed for these expenditure items, and the data are quite noisy. In order to ensure extreme outliers are not driving the reported results, we report results using expenditures truncated at the 99.5th percentile. Results using the untruncated expenditures are qualitatively similar with larger standard errors, and slightly larger point estimates. The impacts on specific household expenditure categories are not well-identified due to this noise.
} 
point estimate, we cannot completely rule out the possibility that the high initial profit women receiving the cash treatment are also investing it in the business and benefit through higher profits.

\subsection{How do the low and high initial profit women differ?}

We have seen that the impact of the grants differs greatly between women with low initial profits and women with high initial profits. It is therefore worth examining in more detail the composition of these two subsamples. The first point to note is that these groups don't differ greatly in the industry or type of business, just in the scale. The low initial profit group is made up of 31 percent food sales, 18 percent beauty and hair, 9 percent sewing, and 42 percent trade, compared to 37 percent food sales, 9 percent beauty and hair, 6 percent sewing and 47 percent trade for the high initial profit group. Even when we look more finely within these broad sectors, we see a similar broad range of types of firms in both subgroups: kenkey and banku (both traditional prepared foods) sellers, dressmakers, beauty salons, used clothes sellers, and retail trade.

In contrast, the scale of the firms differs substantially. Table 6 compares the pre-treatment characteristics of these two subgroups of female firms to each other and to the male-owned firms. The final column also offers a comparison to the sample of female microenterprises from Sri Lanka used in de Mel et al. (2009a). We see that mean and median monthly profits for the low initial profits female subsample is $37-38$ cedis, approximately US $\$ 1$ per day, while mean and median profits are 4 to 6 times this level in the high profit group. Similarly, mean and median sales differs by a factor of 5 to 6 between the low and high initial profit groups. Mean capital stock for the low initial profits group is 251, versus 456 for the high profits group. Comparing to the other two groups, we see that the high initial profit females have larger profits than the average male-owned firms in the sample, while the low initial profits group are similar in size to the female-owned firms in the Sri Lankan study.

Table 6 also shows that women in the high initial profits group are more educated, have richer households (which may be a consequence of the higher profits rather than a cause), are more likely to keep accounts and to have had a formal loan, and have been in business slightly longer than the low initial profits firms. When it comes to the reasons for choosing a particular sector, women in the high profits group are more likely to say they chose their sector for earnings potential and less likely to say they chose it because it had a low capital requirement. 
Overall this paints a picture of the low profits group as much smaller in size, with subsistence level income. For this group we see no impact of the grants on business profits. This is consistent with the finding in Sri Lanka, where the grants had no impact on female-owned businesses. The Sri Lankan businesses are similar in scale to the low initial profits female firms in Ghana - the 95th percentile of profits is only 70 per month in the Sri Lankan sample, which is the 10th percentile of profits for the high initial profit group in Ghana. So for the types of female-owned businesses in Ghana that are similar in scale to those in Sri Lanka, we obtain similar results. Such businesses fit the hypothesis of Emran et al. (2007) that many of the women drawn into subsistence self-employment have very low efficient scale and are there only because of labor market imperfections. As a result, according to our models, neither cash nor in-kind grants should have any long-term impacts on business profitability for these types of low productivity firms. The difference is that the Ghanaian sample also includes a group of more successful female-owned businesses with larger scale, who do show increased profit growth from at least the in-kind treatment.

\section{Why does the impact of cash and in-kind treatments vary?}

We now examine more in detail the possible reasons for the difference between the impact of cash and in-kind grants, particularly for women. We first discuss whether the RTI models can account for this difference.

The only way that the RTI models we presented in the conceptual section can account for a difference between the two treatments is if the in-kind treatment $E_{t}$ cannot be liquidated immediately and the firm has already reached its steady-state. If this is the case, profits and capital are predicted to rise above their steady state after the in-kind treatment, but only until illiquid capital can be divested.

This effect is unlikely to be prominent in our study. There is a relatively long lag between treatment and ex post surveys. The time lag between receiving a grant and the immediately subsequent survey is nearly 3 months. For those who received the grant after round 2, there is an interval of nearly 12 months between receiving the grant and the last survey round. For those receiving the grant after round 3, the time interval is 9 months. Given that recipients of in-kind grants invest in raw materials, inventories, or simple equipment, it would be easy to decapitalize in-kind grants between treatment and the next survey round. Furthermore, as we 
will see below, there is no evidence of divestment of the in-kind grants.

Another possibility is to modify the RTI setup to allow for learning. To see this formally, remember that in the RTI models the steady state capital stock is set by equating the marginal return to capital $\pi^{\prime}\left(k^{*}, \theta\right)$ to the relevant discount rate - either $\rho$ or $r$ or $\tau$, depending on the version of the model. If the entrepreneur believes $\theta$ to be lower than its true value, say, $\theta^{e}<\theta$, then the firm may stop growing before reaching its true steady state. Having been forced to expand thanks to an in-kind grant, the entrepreneur may realize that he or she can successfully handle a larger firm, i.e., that $\theta>\theta^{e}$. If there are enough entrepreneurs with $\theta^{e}<\theta$, this could explain our results.

Is there evidence in support of this hypothesis in the data? Prior to treatment, respondents were asked whether they expected sales to increase if they invested more capital. Entrepreneurs for whom $\theta^{e}<\theta$ should respond negatively to this question. If learning explains our results, the effect of the in-kind treatment should be largest for entrepreneurs who expect the lowest increase in sales from increasing capital. We test this hypothesis and find instead that the inkind treatment has larger - not smaller - effects for firm owners who expected to see a larger increase in sales from investing more capital. There is therefore little evidence for the learning hypothesis in the data.

We thus have to turn to potential explanations that focus on asset non-integration, such as internal and external pressure. The surveys contain variables that proxy for the degree of selfcontrol and the degree of external pressure to share facing business owners. With the exception of the "high capture" dummy which we examined in Table 4, treatment randomization was not stratified on any of these variables. Our analysis should therefore be considered exploratory in nature.

We have four measures which each measure an aspect of self-control and the ability to save cash, all of which were measured pre-treatment. The first two refer to actual saving behavior as reported by respondents before treatment: whether the respondent used a susu collector and whether the respondent agrees or strongly agrees with the statement "I save regularly" (which two-thirds of respondents do). These first two variables have the advantage that they capture actual, not hypothetical, behavior. But they could potentially be affected by external pressure, for instance if someone is unable to save because of a pressure to redistribute, or enters in a contract with a susu collector to keep money away from a prying husband, as in Anderson and Baland (2002). The other two variables we use are the discount rate and measure of hyperbolicity, 
which are less subject to this possible confounding effect, and are thus arguably more reliable. We also extract the common signal in these four variables by forming a principal component, which we call "lack of self-control". ${ }^{14}$ High scores indicate a lower likelihood of using a susu and of saving regularly, and a higher likelihood of being hyperbolic and of having a high discount rate. The lack of self-control index is thus the common component of using a susu and saving regularly that is correlated with hyperbolic time preferences.

The first five columns of Table 7 estimate model (8) to examine the heterogeneity in the treatment effect with respect to these self-control variables for the pooled sample in panel A, and for females only in panel B. Point estimates show a larger impact of the cash treatment when the firm owner uses a susu, saves regularly, is patient, and is not hyperbolic. The signs of the coefficients on the interaction with cash treatment for each of the four variables are consistent with the idea that lack of self-control is associated with a smaller increase in business profits from the cash treatment. Column 5 shows that when we combine all these variables into an index of self-control using principal components, the interaction between cash treatment and lack of self-control is significant at the 5 percent level. This implies that the effect of the cash treatment for someone with the most self-control is 29.2, which is similar to the average impact of the in-kind treatment of 30.9 in column 4 of Table 3 . The female only sample in panel B shows a similar pattern in terms of signs of the coefficients, but interaction terms are not significant, possibly because the sample is smaller.

We also investigate whether cash and in-kind grants have a differentiated effect on capital retention depending on entrepreneur self-control. Figure 5 presents the evolution of capital stock after treatment, contrasting between cash and in-kind grants for entrepreneurs with and without self-control. The Figure shows that in-kind grants are retained in the firm and lead to further accumulation of capital whether the entrepreneur lacks self-control or not - although the effect on capital accumulation is strongest for those with low self-control. In contrast, cash grants have, if anything a negative effect on capital accumulation among low self-control entrepreneurs while the effect is positive and growing for those with high self-control. This confirms that the reason why in-kind grants have a strong positive effect on profit is related to self-control issues and their effect on the accumulation of capital. If we further interact the self-control index with high baseline profits, we find that self-control affects the impact of treatment only for female entrepreneurs with high baseline profits. For those with low initial profits, treatment

\footnotetext{
${ }^{14}$ The principal component has mean zero, and ranges from -1.67 to 2.26 .
} 
has no effect irrespective of self-control. If we are willing to regard baseline profits as proxy for ability $\theta$, this suggests that self-control is an impediment to growth only for more able female entrepreneurs, who have more potential for growth.

Next we examine whether the pattern of heterogeneous treatment effects in the sample is consistent with external pressure. We first investigate capture by spouses. Unmarried individuals are not, by definition, subject to capture by a spouse. Consequently, if capture by a spouse is the main reason why cash treatments do not raise profit, this should not affect unmarried entrepreneurs - especially women. To test this hypothesis, we interact treatment with a married dummy and expect the cash treatment effect now to be positive and the interaction term to be negative, especially for female entrepreneurs. The percentage of unmarried individuals in our sample is $34 \%$ for females and $35 \%$ for males. Results, presented in columns (1) and (2) of Table 8, show that the cash treatment remains non-significant for female entrepreneurs. None of the interaction terms is statistically significant but point estimates for females are positive for cash and negative for in-kind, which is the opposite of what the external pressure hypothesis predicts. Married status is also not (negatively) correlated with baseline capital stock, as should be case if marriage leads to more capture.

Next we examine the determinants of bargaining power between married entrepreneurs. The hypothesis is that less of the cash and in-kind treatment is taxed away from the business when a married entrepreneur has more bargaining power with his or her spouse. We expect the effect of bargaining to be stronger for female entrepreneurs, given their subordinate status in traditional society. The first proxy for bargaining power is the share of assets brought to marriage by the owner. This information is available for 397 married respondents.

As shown in columns (3) and (4) of Table 8, point estimates are insignificant and do not go in the expected direction: we would expect those who bring a higher share of assets into the marriage to have more bargaining power, yet the interaction of this with the cash treatment is negative. We also test (not shown) whether the share of assets brought to marriage is correlated with baseline capital stock, as should be the case if entrepreneurs with more bargaining power are less subject to spouse taxation and can accumulate more over time. We find no evidence of this.

We investigate other possible determinants of intra-household bargaining power, such as differences between spouses in age and education level. We expect older, more educated spouses to have more bargaining power. The results, shown, in columns (5) to (8) of Table 8, are once 
again not significant and the point estimates of the interaction terms are small. In columns (9) and (10) we use more subjective data: namely whether the respondent agrees that they can spend their income without consulting their spouse (72 percent of women and 71 percent of men say they can). By construction, this information is only available for married respondents. We again find no statistically significant interaction effect with the cash treatment and point estimates small for women.

The last proxy for bargaining power that we investigate is the share of individual income in total household income or expenditure. Much of the literature on intra-household bargaining has used relative incomes as proxy for bargaining power, either because having more income gives more agency, or because earning an income outside the home results from having more bargaining power. We construct our proxy using income and consumption information at baseline. We expect spouses with a larger income share to retain more of the treatment and thus to have a larger treatment effect. ${ }^{15}$ Results, presented in columns (11) to (14) of Table 8, show no statistically significant interaction.

We next turn to external pressure more broadly defined, i.e., including individuals other than the spouse. The first proxy we consider is the absolute size of the household. Presumably, the more members a household has, the more people there are who can put pressure on the respondent to share cash and in-kind grants. Pressure need not be explicit, though. If respondents are altruistic towards other members of their household, they may feel the need to share the grants with them instead of investing. In this case the needs of others are internalized and no explicit pressure need be applied.

The next proxy is whether the firm owner says they feel a lot or some pressure to share extra business income with other household members rather than invest in the business. 23 percent of females and 22 percent of males claim to feel this pressure. This information was only collected in the last survey round, after treatments, so results should be considered as suggestive only. There is, however, no difference in means on this variable between treated and untreated samples. As a proxy for pressure from outside the household, we include the number of siblings in the Accra/Tema area. Presumably, the more siblings a person has, the more relatives there

\footnotetext{
${ }^{15}$ Share of household income or consumption is not an ideal proxy for our purpose since it also reflects entrepreneurial ability, and more able entrepreneurs may benefit more from treatment. For a given ability level, a higher share of household income also implies that other household members are not high earners and hence that the entrepreneur is more capital constrained. This too would predict a higher treatment effect. Given that we find no significant effect, this issue is moot.
} 
are who could put pressure on the respondent to share the grants - or the more relative there are towards whom the respondent may have altruistic feelings.

Results are presented in Table 9. When we look at the full sample we do not see any significant interactions between the cash treatment effect and proxies for external pressure. The size of the interaction terms on pressure to share is too small to generate large positive impacts of the cash treatment. When we consider the females-only sample in panel B, we get a significant but positive interactions on household size and on the number of siblings in the area - i.e., the opposite sign of what we would expect from external pressure. This is nevertheless consistent with Grimm et al. (2010) who find a positive impact of nearby networks on firm growth. These findings are also in line with the lack of sizeable or significant interaction with low capture seen in Table 4 for the low capture/high capture variable we stratified on.

Taken together, the evidence from Tables 7, 8 and 9 appears more consistent with self-control rather than external pressure being the cause of the lack of an effect of the cash treatment. One might however worry that people who have trouble saving or have time-inconsistent preferences and high discount rates are also those who more external pressure.

To examine this possibility, we test in Table 10 whether proxies for external pressure are significantly associated with the lack of self-control index. In addition to the variables used to proxy external pressure in Table 7, we also consider: whether they think inventories and equipment held in the business are a good way of saving money so others don't take it (55 percent of women and 72 percent of men say yes); whether the respondent had been compelled to give money to their spouse in the three months prior to the baseline (10 percent of married women and 15 percent of married men said yes); and whether their spouse is supportive of them running a business (84 percent say yes for both men and women).

We cannot reject the null hypothesis that none of the proxies for external pressure are associated with the self-control index. While measuring external pressure is difficult, if selfcontrol was merely proxying for external pressure, we would expect some relationship, yet there is none. We therefore conclude that there is more evidence to support the hypothesis that the difference between cash and in-kind treatments is driven by self-control issues than by external pressure. 


\section{Conclusions}

We find that the effect of in-kind and cash grants is significantly different, a finding that is difficult to reconcile with models of accumulation that take either a standard Ramsey form, or allow for pure time inconsistence. These results suggest a lack of asset integration, as if entrepreneurs fail to take consumption and investment decisions jointly. The difference between in-kind and cash grants is suggestive either that inventories and equipment serve as a selfcommitment device against impulse purchases - or that entrepreneurs evade a social solidarity tax, by household members and relatives, on the cash flow of the firm but not its equipment and inventories.

We find that cash and in-kind grants have significantly different effects for female entrepreneurs in Ghana. In-kind grants lead to large increases in business profits, but only for female-owned firms which were initially more profitable - subsistence firms don't grow when given more capital. In-kind grants also lead to large increases in business profits for men, while the effect of cash grants is less robust - we find large positive and significant effects when we don't condition on baseline profits, but smaller and insignificant effects when we do. The difference between cash and in-kind treatments is strongest among successful female entrepreneurs, that is, those with high pre-treatment profits.

We seek to identify the reason for the difference in treatment between cash and in-kind grants, i.e., whether it originates in self-control difficulties or in pressure from household and family members. The fact that the difference in treatment effects is only statistically significant among female entrepreneurs is suggestive of external pressure: given the social context, women entrepreneurs are expected to be subjected to pressure from husband and children. However, we fail to find confirmatory evidence for this hypothesis when interact treatment with proxies for external pressure. In contrast, we find that individuals with more self-control difficulties respond better to treatment in terms of profits. There is no evidence that female entrepreneurs lack self-control more than men.

Ghana offers a setting where women are the majority of small business owners, and in this setting we find the top 40 percent of women in terms of profitability look similar or more profitable than the average male firm. Such a large group of relatively high achieving women is not present in the Sri Lankan sample of de Mel et al. (2009a), and indeed the remaining group of subsistence-level Ghanaian female business owners have similar negligible business impacts from the grants as the group of women in the Sri Lankan experiment. 
The results offer partially good news for advocates of directing microfinance at women. We do find in Ghana a relatively large group of women whose profits increase a lot when given in-kind transfers. Microcredit has been argued as allowing individuals to overcome present-bias by providing self-discipline and encouragement through regular payments and group meetings (Bauer et al, 2010). If this is true, the effectiveness of micro loans in improving business outcomes is likely to resemble the effect of in-kind grants in our experiment. However, our findings suggest this effect to be more powerful for women who are already earning more to begin with, suggesting possible limits on the ability of capital alone to generate business growth among poor subsistencelevel female enterprises. Moreover, as in prior work in Sri Lanka and Mexico, the results show that the average male-owned microenterprise gains a lot from being granted additional access to capital. This suggests that microfinance programs that focus primarily on women may be ignoring a large group of enterprises with a need for more capital.

Finally, our results suggest that loans and grants intended to help female enterprises grow would work better if disbursed in kind, not in cash. Banks already seem to know this, given that bank loans are nearly always in kind: when borrowing to purchase a house, car, or machine, the bank does not hand over the money to the borrower but rather pays the supplier/seller directly. ${ }^{16}$ If their objective is to foster enterprise development, and not just saving, microfinance organizations may want to adopt similar practices.

\section{References}

Andersen, Stephen, Glenn W. Harrison, Morten I. Lau, and E. Elisabeth Rutstrom (2008) "Risk Aversion in Game Shows", Research in Experimental Economics, 12: 361-406

Anderson, Siwan, and Jean-Marie Baland (2002). "The Economics of Roscas and Intrahousehold Resource Allocation", Quarterly Journal of Economics, 117(3): 963-95, August

Besley, Timothy (1995) "Savings, credit and insurance", pp. 2123-2207 in Jere Behrman and T.N. Srinivasan (eds.) Handbook of Development Economics Volume III, Elsevier: Amsterdam.

Baland, Jean-Marie, Catherine Guirkinger and Charlotte Mali (2007) "Pretending to be Poor: borrowing to escape forced solidarity in credit cooperatives in Cameroon", Mimeo. University of Namur.

Banerjee, Abhijit and Esther Duflo (2009) "The Experimental Approach to Development

\footnotetext{
${ }^{16}$ This also applies to letter-of-credit-based lending for imports. This even applies, albeit partially, to lines of credit given that the bank observes the identity of the payee - and will object/block payment if an enterprise's overdraft facility is used to pay for consumption items, such as a new car.
} 
Economics", Annual Review of Economics 1:151-78.

Banerjee, Abhijit, Esther Duflo, Rachel Glennester and Cynthia Kinnan (2010) "The Miracle of Microfinance? Evidence from a Randomized Evaluation", BREAD Working Paper no. 278.

Banerjee, Abhijit and Sendhil Mullanaithan (2010) "The Shape of Temptation: Implications for the Economic Lives of the Poor", MIT Working Paper no 10-9.

Bauer, Michal, Julie Chytilova and Jonathan Morduch (2010) "Behavioral Foundations of Microcredit: Experimental and Survey Evidence from Rural India", IZA Working Paper no. 4901.

Bigsten, Arne, Paul Collier, Stefan Dercon, Marcel Fafchamps, Bernard Gauthier, JanWillem Gunning, Anders Isaksson, Abena Oduro, Remco Oostendorp, Cathy Patillo, Mans Soderbom, Francis Teal, Albert Zeufack, and Simon Appleton (2000) "Rates of Return on Physical and Human Capital in Africa's Manufacturing Sector", Economic Development and Cultural Change, 48(4): 801-27.

Bjorvatn, Kjetil, Lars Ivar Oppedal Berge, and Bertil Tungodden (2011) "Human and financial capital for microenterprise development: Evidence from a field and lab experiment", NHH and CMI (mimeograph)

Bruhn, Miriam and David McKenzie (2009) "In Pursuit of Balance: Randomization in Practice in Development Field Experiments", American Economic Journal: Applied Economics 1(4): 200-32.

Brune, Lasse, Xavier Gine, Jessica Goldberg, and Dean Yang (2011). "Commitments to Save: A Field Experiment in Rural Malawi", University of Michigan, May (mimeograph).

Camerer, Colin, Linda Babcock, George Loewenstein, and Richard Thaler (1997). "Labor Supply of New York City Cabdrivers: One Day at a Time", Quarterly Journal of Economics, 112: 407-41.

Charlier, Florence (1999) "Saving or Sharing: The African Households' Dilemma", Stanford Department of Economics Ph.D. Dissertation.

Deaton, Angus (2010) "Instruments, Randomization, and Learning about Development", Journal of Economic Literature, 48(2): 424-55

De Mel, Suresh, David McKenzie, and Christopher Woodruff (2008). "Returns to Capital: Results from a Randomized Experiment." Quarterly Journal of Economics 123(4): 1329-72.

De Mel, Suresh, David McKenzie, and Christopher Woodruff (2009a) "Are Women more Credit Constrained? Experimental Evidence on Gender and Microenterprise Returns." Ameri- 
can Economic Journal: Applied Economics 1(3): 1-32.

De Mel, Suresh, David McKenzie and Christopher Woodruff (2009b) "Measuring microenterprise profits: Must we ask how the sausage is made?", Journal of Development Economics 88(1): 19-31

Di Falco, Salvatore and Erwin Bulte (2009) "The Dark Side of Social Capital: Kinship, Consumption, and Investment", Mimeo. University of Kent.

Duflo, Esther, Michael Kremer and Jonathan Robinson (2010) "Nudging Farmers to Use Fertilizer: Theory and Experimental Evidence from Kenya", American Economic Review forthcoming.

Duflo, Esther and Christopher Udry (2004) "Intrahousehold Resource Allocation in Côte d'Ivoire: Social norms, separate accounts, and consumption choices" , NBER Working Paper no. 10498.

Emran, M. Shahe, AKM Mahbub Morshed and Joseph Stiglitz (2007) "Microfinance and Missing Markets", Mimeo. George Washington University.

Fafchamps, Marcel, Christopher Udry, and Katherine Czukas (1998). "Drought and Saving in West Africa: Are Livestock a Buffer Stock?", Journal of Development Economics, 55(2): 273-305, April

Fafchamps, Marcel, David McKenzie, Simon Quinn and Christopher Woodruff (2010) "Using PDA consistency checks to increase the precision of profits and sales measurement in panels", Journal of Development Economics, forthcoming.

Grimm, Michael, Flore Gubert, Ousman Koriko, Jann Lay and Christophe Nordman (2010) "Does forced solidarity hamper entrepreneurial activity? Evidence from seven West-African countries", Mimeo. International Institute of Social Studies, Eramus University Rotterdam.

Harrison, Glenn, Morten I. Lau, and E. Elisabeth Rutstrom (2007). "Estimating Risk Attitudes in Denmark: A Field Experiment", Scandinavian Journal of Economics, 109(2): 341-68.

Jakiela, Pamela and Owen Ozier (2011) "Does Africa need a rotten kin theorem? Experimental evidence from village economies", Mimeo. University of Washington, St Louis.

Karlan, Dean and Jonathan Zinman (2010) "Expanding Microenterprise Credit Access: Using Randomized Supply Decisions to Estimate the Impacts in Manila", Mimeo. Yale University.

Laibson, David (1997) "Golden Eggs and Hyperbolic discounting", Quarterly Journal of Economics 112(2): 443-77.

Lee, David (2009) "Training, Wages, and Sample Selection: Estimating Sharp Bounds on 
Treatment Effects", Review of Economic Studies 76(3): 1071-1102.

McKenzie, David (2011) "Beyond baseline and follow-up: The case for more $\mathrm{T}$ in experiments", World Bank Policy Research Working Paper no. 5639.

McKenzie, David and Christopher Woodruff (2008) "Experimental Evidence on Returns to Capital and Access to Finance in Mexico", World Bank Economic Review 22(3): 457-82

Platteau, Jean-Philippe (2000) Institutions, Social Norms and Economic Development. Harwood Academic Publishers: Amsterdam.

Ravallion, Martin (2009) "Should the Randomistas Rule?", The Economists Voice 6(2).

Schündeln, Mathias (2006) "Modeling Firm Dynamics to Identify the Cost of Financing Constraints in Ghanaian Manufacturing", Mimeo. Harvard University.

Somville, Vincent (2011). "Daily Collectors, Public Good Provision, and Private Consumption: Theory and Evidence from Urban Benin", Department of Economics, Namur University (mimeograph)

Spears, Dean (2009) "Dosas by the Dozen: Theory and Evidence of Present Bias in Microentrepreneurs", Institute for Financial Management and Research Working Paper no. 27

Udry, Christopher (1996). "Gender, Agricultural Production and the Theory of the Household", Journal of Political Economy, 104(5): 1010-1046, October

Udry, Christopher and Santosh Anagol (2006) "The Return to Capital in Ghana", American Economic Review Papers and Proceedings 96(2): 388-93. 


\section{Appendix 1: Steady state firm size with time inconsistency}

Let $\tau$ denote the one period-ahead discount rate: ${ }^{17}$

$$
\frac{1}{1+\tau} \equiv \beta \delta
$$

Let $k^{s}$ be the level of capital that satisfies:

$$
\pi^{\prime}\left(k^{s}, \theta\right)=\tau .
$$

Is $k^{s}$ the steady state capital of a time inconsistent entrepreneur? It depends on whether the decision maker is sophisticate or myopic, that is, whether he or she realizes that future decisions were taken according to (3) or not.

Suppose the decision maker is sophisticate and sets $k_{t}=k^{s}$. Is this a steady state? The Euler equation between $t$ and $t+1$ is:

$$
1+\pi^{\prime}\left(k_{t+1}, \theta\right)=\frac{1}{\beta \delta} \cdot \frac{u_{t}^{\prime}\left(c_{t}\right)}{u_{t+1}^{\prime}\left(c_{t+1}^{P}\right)}
$$

where $c_{t+1}^{P}$ denotes the household's predicted future decision about $c_{t+1}$. If the household is myopic, $c_{t+1}^{P}$ is expected to coincide with the decision made at time $t$, i.e., as given by (2). If the household is sophisticate, it is the correctly anticipated decision taken at time $t+1$ as given by the solution to (3).

First note that if $c_{t+1}^{P}=c_{t}$, then $u_{t}^{\prime}\left(c_{t}\right)=u_{t+1}^{\prime}\left(c_{t+1}^{P}\right)$ and setting $k_{t}=k^{s}$ satisfies the above Euler equation. If the entrepreneur is sophisticate and sets $k_{t}=k^{s}$, she realizes that the decision problem and Euler equation at $t+1$ will be identical to those at $t$. Hence she correctly anticipates that $c_{t+1}^{P}=c_{t}$. It follows that $k^{s}$ is the steady state level of firm capital for a sophisticate entrepreneur.

If the entrepreneur is myopic and sets $k_{t}=k^{s}$, she incorrectly believes that she will be more patient next period. Let $c_{t+1}^{M}$ denote the consumption level she sets for $t+1$, not realizing that at $t+1$ she will want to increase consumption beyond $c_{t+1}^{M}$. At $k_{t}=k^{s}$ the entrepreneur expects $c_{t+1}^{M}<c_{t}$, which implies that $u_{t+1}^{\prime}\left(c_{t+1}^{P}\right)>u_{t}^{\prime}\left(c_{t}\right)$. Hence $k^{s}$ does not satisfy the Euler equation (11) and is not a steady state. For a myopic decision maker, the steady state capital $k^{m}$ is such that $c_{t}=c_{t+1}$ and $c_{t+1}^{M}=c_{t+2}^{M}$. Since $c_{t+1}^{M}<c_{t+1}$, it follows that $\frac{u_{t}^{\prime}\left(c_{t}\right)}{u_{t+1}^{\prime}\left(c_{t+1}^{M}\right)}<1$, which in turn implies that $k^{s}<k^{m}$ and

$$
\pi^{\prime}\left(k^{m}, \theta\right)>\tau
$$

\footnotetext{
${ }^{17}$ It is clear that $\tau>\rho$. If, as is likely, $\tau>r$, the household will never want to set $w>0$. So we ignore savings here.
} 


\section{Appendix 2: Robustness to Attrition}

Attrition in the panel comes from firms closing, refusing to answer the survey, or answering the survey but not providing profits data. Appendix Table A1 provides attrition rates per round for the experimental sample. Recall that we eliminated firms which closed or refused to answer the round 2 survey before undertaking the randomization. As a result, attrition from the survey is zero by definition for the experimental group in rounds 1 and 2, although there is some item non-response on profits. Over the course of our experiment we observe 6 percent of the firms closing, with this rate not varying between treatment and control. We were able to keep attrition fairly low over waves 3 through 6 of the survey, and exerted additional effort in round 6 to try and track and induce responses by firms that had attrited in previous waves. As a result, only 8 percent of the sample is not present in wave 6 , although 11 percent do not report profits data. Nevertheless, overall attrition rates are higher for the control group than either treatment group, likely reflecting either an implicit obligation felt by those receiving grants to continue in the survey, or discouragement of those who weren't randomly selected for the grants. Whilst statistically significant, the difference in attrition magnitudes are not that large, which should limit the impact of this differential attrition on our results.

To examine how robust our results are to attrition, we use the bounding approach of Lee (2009) to construct upper and lower bounds for the treatment effect. The key identifying assumption for implementing these bounds is a monotonicity assumption that treatment assignment affects sample selection only in one direction. In our context, this requires assuming that there are some firms who would have attrited if they had not been assigned to treatment, but that no firm attrits because of getting assigned to treatment. This seems plausible in our context. We then construct the bounds by trimming either the top or the bottom of the distribution of profits for the treatment groups by the relative difference in attrition rates between treatment and control. This is done on a wave by wave basis, and involves trimming up to 6 percent from the top or bottom of the distribution of the treatment group.

Table A2 shows the results of estimating these Lee bounds. Columns 1 and 2 repeat the main trimmed estimates from Table 3 for comparison. These lie between the bounds estimated in columns 3 and 4 using OLS, and in columns 5 and 6 using fixed effects. We see that our parameter estimates are much closer to the upper bounds than the lower bounds, which reflects the skewed distribution of profits.

The lower bounds occur only if it is the most profitable control firms that attrit. However, 
a panel regression predicting attrition in the control group (in the form of missing profits) as a function of the previous period's profits finds that having the previous period's profits in the top 10 percent or in the bottom 10 percent, or below the median has no significant effect on attrition. Similarly, we firms which experience large changes in profits over two waves are no more likely to attrit in the subsequent wave. As a result, it seems attrition in the control group is not associated with previous levels or previous changes in profits. Given this, it seems reasonable to assume that profits are either missing at random, or missing in firms which suffer negative shocks that cause the firm to shut down or the owner to be sick in the survey period. That is, there seems reason to believe either the panel estimates in columns (1) or (2), or the upper bound estimates which are based on the least successful control firms attriting. There seems to be no evidence to support the most successful control firms attriting, which is what the lower bound estimates assume. We therefore conclude the main results do not seem to be driven by attrition.

\section{Appendix 3: Is it reasonable to pool effects over time?}

To test for pooling of treatment effects we allow the coefficients on treatment in equation (1) to vary with time since treatment. In doing this, one should note that we only observe effects 12 months after treatment for the firms treated after round 2, which is half of the treated sample. In contrast, we observe effects at 3 months and 6 months for the entire treated sample, and effects at 9 months for almost all the sample (excepting the 18 firms treated after round 4). Appendix Table A3 then shows the results. We cannot reject that the impact of treatment does not vary with time since treatment for the pooled sample, and for the male sample, or for the female sample using OLS. For the female sample using fixed effects, the p-value for equality of in-kind treatment effects over time is 0.057 , offering some suggestion that the impact is greater with more time since treatment. 
Figure 1: Post-treatment CDFs of Monthly Profits for Males by Treatment Group

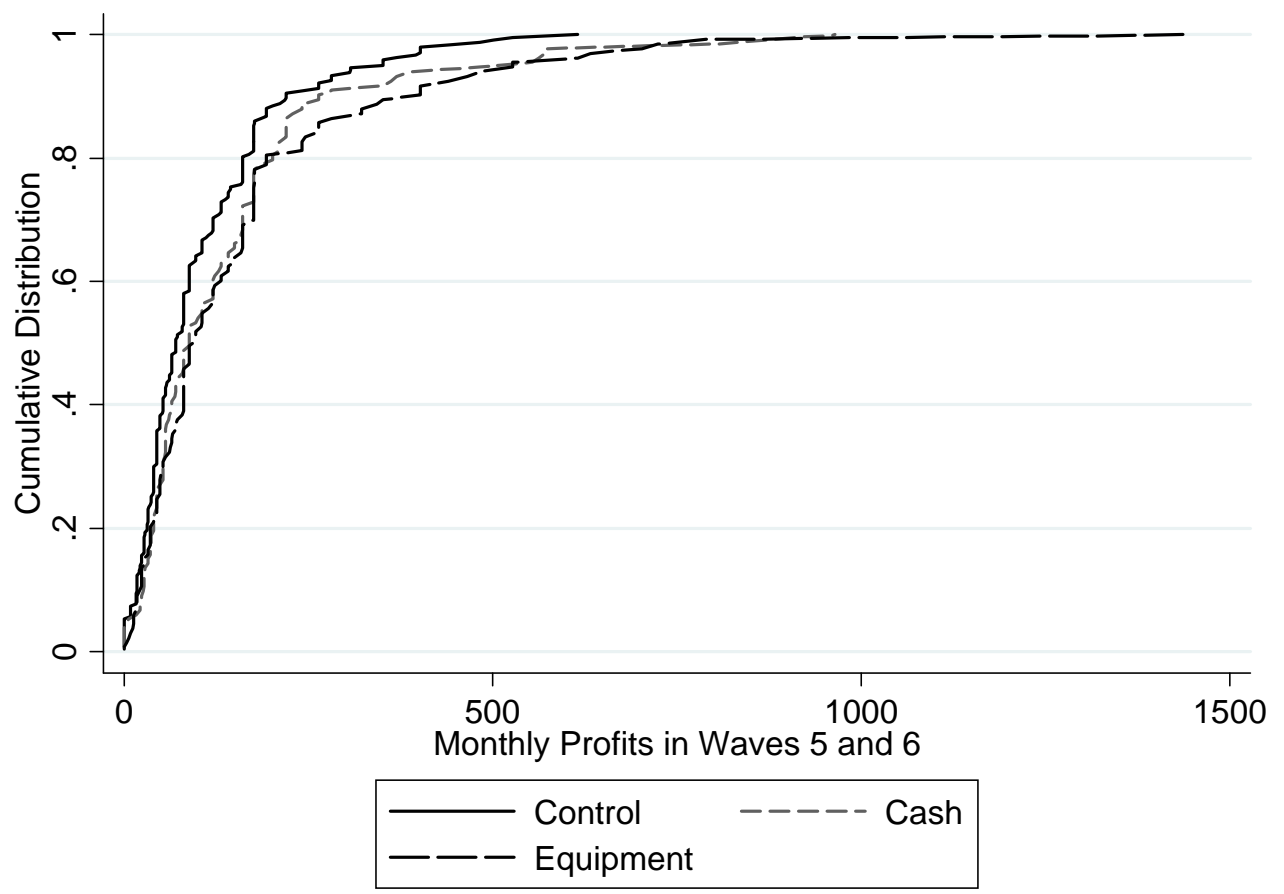

Figure 2: Post-treatment CDFs of Monthly Profits for Females by Treatment Group

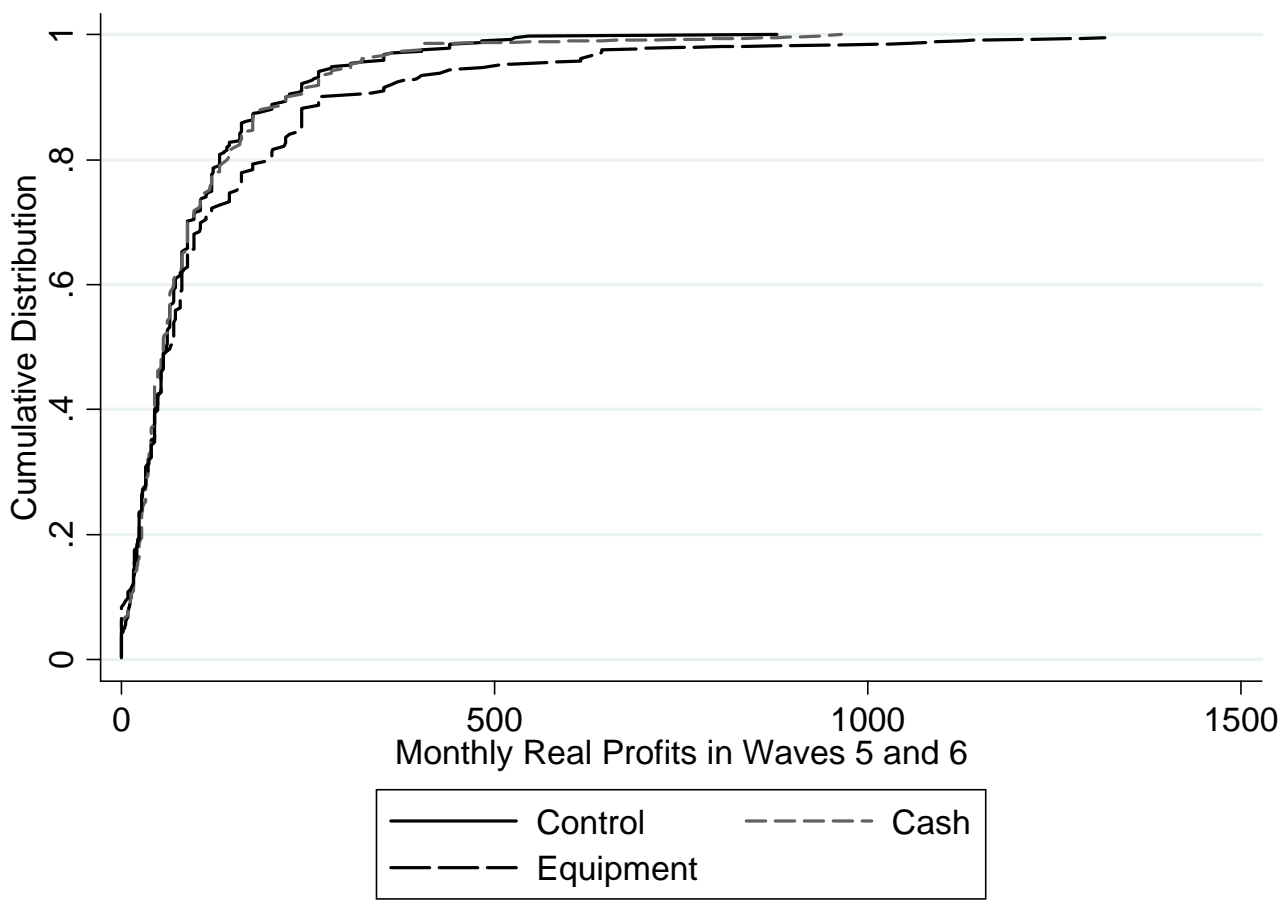


Figure 3: Post-treatment CDFs of Capital Stock for Males by Treatment Group

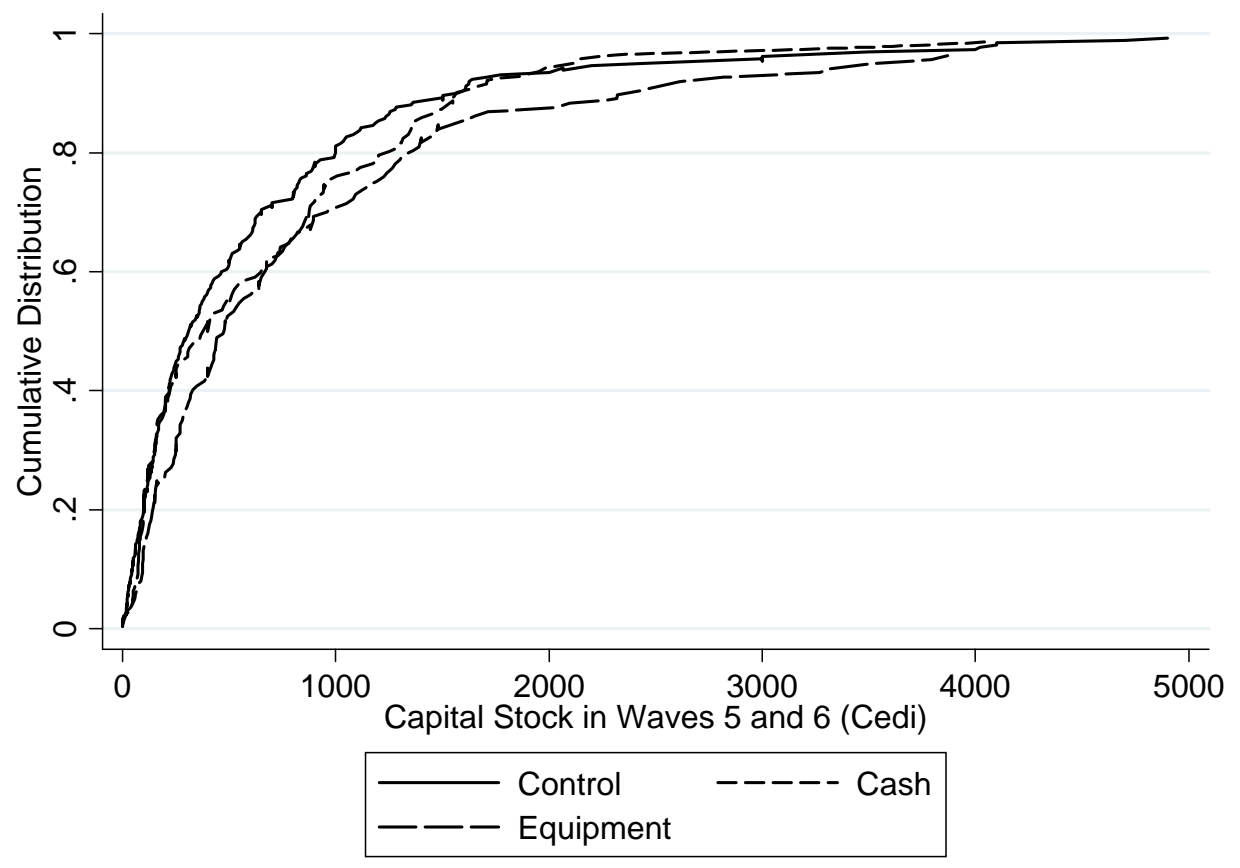

Figure 4: Post-treatment CDFs of Capital Stock for Females by Treatment Group

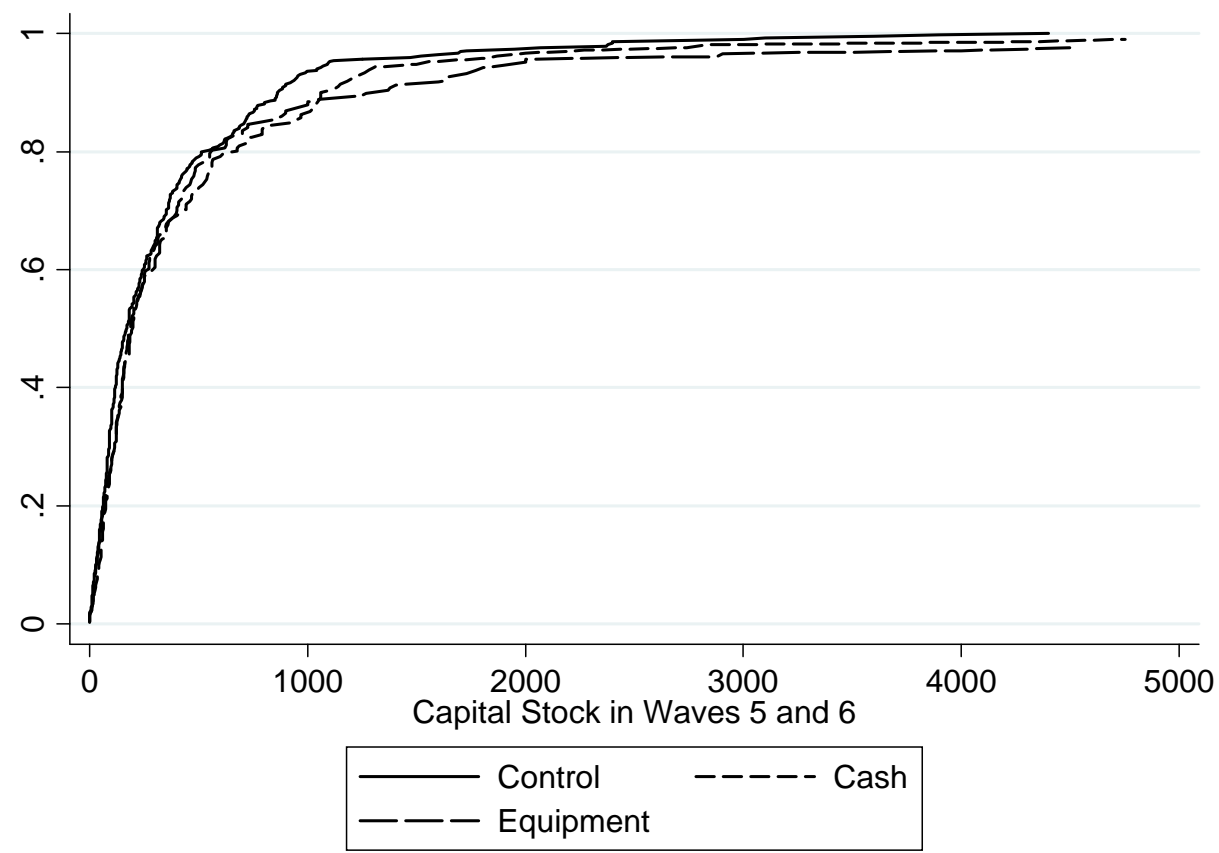


Figure 5. Evolution of Capital Stock After Treatment

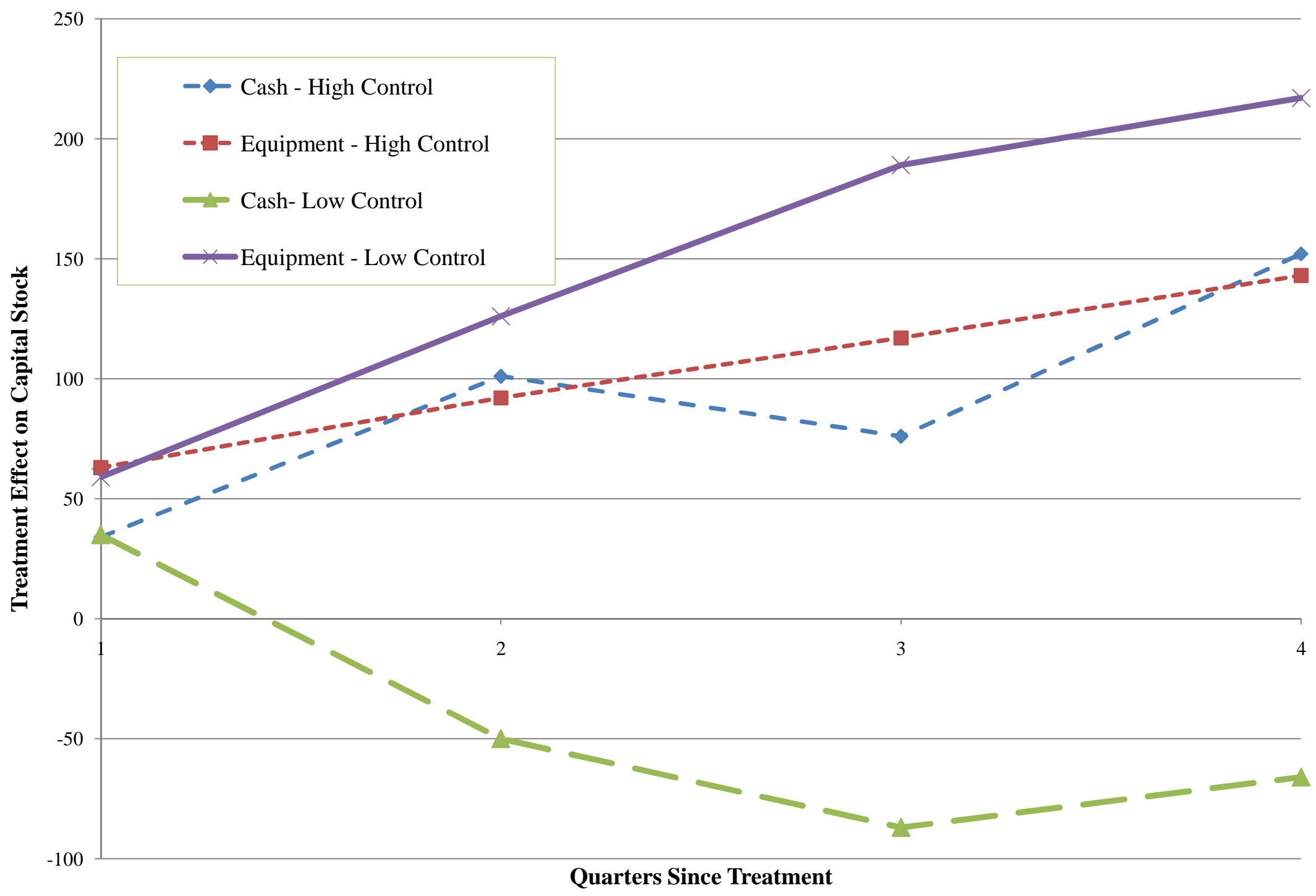


Table 1: Characteristics of Microenterprises and Verification of Randomization

\begin{tabular}{|c|c|c|c|c|c|c|c|c|}
\hline & \multicolumn{4}{|c|}{ Full Sample } & \multicolumn{4}{|c|}{ Trimmed Sample } \\
\hline & $\mathrm{N}$ & Control & Cash & In-kind & $\mathrm{N}$ & Control & Cash & In-kind \\
\hline \multicolumn{9}{|l|}{ Variables Using to Stratify or Match } \\
\hline Monthly profits in January 2009 & 781 & 128 & 132 & 131 & 753 & 103 & 99 & 115 \\
\hline Female & 793 & 0.60 & 0.60 & 0.61 & 765 & 0.62 & 0.62 & 0.62 \\
\hline High Capture & 793 & 0.58 & 0.58 & 0.57 & 765 & 0.58 & 0.58 & 0.57 \\
\hline High Baseline Capital Stock & 793 & 0.49 & 0.49 & 0.49 & 765 & 0.48 & 0.48 & 0.48 \\
\hline Male in Male dominated industry & 793 & 0.18 & 0.19 & 0.18 & 765 & 0.18 & 0.18 & 0.18 \\
\hline Male in Mixed industry & 793 & 0.21 & 0.21 & 0.21 & 765 & 0.20 & 0.20 & 0.20 \\
\hline Female in Female dominated industry & 793 & 0.29 & 0.29 & 0.29 & 765 & 0.30 & 0.29 & 0.30 \\
\hline Female in Mixed industry & 793 & 0.31 & 0.31 & 0.31 & 765 & 0.32 & 0.32 & 0.32 \\
\hline \multicolumn{9}{|l|}{ Other Variables } \\
\hline Monthly profits in October/November 2008 & 729 & 124 & 133 & 104 & 704 & 93 & 129 & 99 \\
\hline Monthly sales in January 2009 & 790 & 724 & 463 & 630 & 762 & 412 & 402 & 595 \\
\hline Number of hours worked in last week & 785 & 58.82 & 60.55 & 57.13 & 757 & 59.03 & 60.64 & 56.64 \\
\hline Total Capital Stock in January 2009 & 784 & 468 & 454 & 418 & 757 & 446 & 438 & 410 \\
\hline Inventories at end of January 2009 & 791 & 258 & 213 & 201 & 763 & 239 & 203 & 198 \\
\hline Uses a Susu Collector & 791 & 0.49 & 0.46 & 0.49 & 763 & 0.49 & 0.46 & 0.51 \\
\hline Business operated out of home & 793 & 0.76 & 0.78 & 0.82 & 765 & 0.77 & 0.78 & 0.83 \\
\hline Age of Firm & 788 & 7.87 & 7.13 & 7.22 & 761 & 7.88 & 7.11 & 7.14 \\
\hline Ever had bank or microfinance loan & 793 & 0.11 & 0.10 & 0.07 & 765 & 0.10 & 0.09 & 0.07 \\
\hline Business has a tax number & 786 & 0.15 & 0.14 & 0.13 & 758 & 0.14 & 0.14 & 0.13 \\
\hline Owner is Married & 791 & 0.65 & 0.64 & 0.67 & 763 & 0.65 & 0.63 & 0.68 \\
\hline Owner's Years of Education & 775 & 8.87 & 8.75 & 9.05 & 749 & 8.81 & 8.70 & 9.00 \\
\hline Owner's Digitspan Recall & 768 & 5.11 & 5.07 & 5.03 & 740 & 5.07 & 5.10 & 4.99 \\
\hline Owner is Akan Speaker & 793 & 0.45 & 0.41 & 0.43 & 765 & 0.46 & 0.41 & 0.43 \\
\hline Owner is Ga/Dangme Speaker & 793 & 0.28 & 0.27 & 0.31 & 765 & 0.29 & 0.27 & 0.32 \\
\hline Owner's Age & 791 & 36.39 & 35.43 & 35.74 & 763 & 36.36 & 35.37 & 35.79 \\
\hline
\end{tabular}

Note: Trimmed Sample eliminates matched groups in which baseline profits for at least one firm

in group exceed 1500 cedis per month

The only differences between groups which are statistically significant at conventional levels are January 2009 sales

and October/November 2009 profits in the trimmed sample. 
Table 2: Correlates of Baseline Capital Stock

\begin{tabular}{|c|c|c|c|}
\hline & (1) & $(2)$ & (3) \\
\hline Hyperbolic Discounter & $\begin{array}{c}-196.1^{* *} \\
(82.13)\end{array}$ & & \\
\hline Low Discount Rate & $\begin{array}{c}94.53 \\
(73.46)\end{array}$ & & \\
\hline Lack of self-control index & & $\begin{array}{l}-60.34 * \\
(32.48)\end{array}$ & \\
\hline Feels pressure to share in household & & & $\begin{array}{c}-201.3 * * \\
(87.38)\end{array}$ \\
\hline Digitspan Recall & $\begin{array}{l}34.02 * \\
(18.24)\end{array}$ & $\begin{array}{l}35.51 * \\
(18.32)\end{array}$ & $\begin{array}{c}44.34^{* *} \\
(18.10)\end{array}$ \\
\hline Raven test score & $\begin{array}{c}13.20 \\
(13.49)\end{array}$ & $\begin{array}{c}15.85 \\
(13.51)\end{array}$ & $\begin{array}{c}21.77 \\
(13.32)\end{array}$ \\
\hline Education Years & $\begin{array}{c}13.95 \\
(11.15)\end{array}$ & $\begin{array}{c}13.42 \\
(11.19)\end{array}$ & $\begin{array}{c}6.674 \\
(11.09)\end{array}$ \\
\hline Female & $\begin{array}{c}-193.9 * * \\
(75.45)\end{array}$ & $\begin{array}{c}-198.5^{* * *} \\
(75.87)\end{array}$ & $\begin{array}{c}-137.8^{*} \\
(75.17)\end{array}$ \\
\hline Age & $\begin{array}{c}13.63 * * * \\
(4.162)\end{array}$ & $\begin{array}{c}14.02 * * * \\
(4.179)\end{array}$ & $\begin{array}{c}12.57 * * * \\
(4.228)\end{array}$ \\
\hline Father's schooling & $\begin{array}{c}1.880 \\
(7.408)\end{array}$ & $\begin{array}{c}2.144 \\
(7.445)\end{array}$ & $\begin{array}{c}0.168 \\
(7.283)\end{array}$ \\
\hline Mother's schooling & $\begin{array}{c}4.200 \\
(8.064)\end{array}$ & $\begin{array}{c}3.842 \\
(8.106)\end{array}$ & $\begin{array}{c}2.374 \\
(8.001)\end{array}$ \\
\hline Constant & $\begin{array}{l}-244.5 \\
(220.8)\end{array}$ & $\begin{array}{l}-263.3 \\
(220.9)\end{array}$ & $\begin{array}{l}-207.3 \\
(220.0)\end{array}$ \\
\hline Observations & 652 & 650 & 621 \\
\hline R-squared & 0.053 & 0.049 & 0.043 \\
\hline
\end{tabular}

Standard errors in parentheses

$* * * p<0.01, * * p<0.05, * p<0.1$ 
Table 3: Main Treatment Effects

Dependent Variable: Real Monthly Profits (Cedi)

\begin{tabular}{|c|c|c|c|c|c|c|c|c|c|c|}
\hline & $\begin{array}{l}\text { (1) } \\
\text { (1) }\end{array}$ & $\begin{array}{l}(2) \\
0 \mid s\end{array}$ & $\begin{array}{l}\text { (3) } \\
F F\end{array}$ & $\begin{array}{l}\text { (4) } \\
F F\end{array}$ & (5) & $\begin{array}{l}(6) \\
0 \mid s\end{array}$ & $\begin{array}{l}\text { (7) } \\
F F\end{array}$ & $\begin{array}{l}\text { (8) } \\
F F\end{array}$ & $\begin{array}{l}\text { (9) } \\
\text { (1) }\end{array}$ & (10) \\
\hline \multirow[t]{2}{*}{ Cash Treatment } & $14.50^{*}$ & 9.59 & 3.96 & 0.48 & & & & & & \\
\hline & (8.68) & (7.32) & (13.89) & (8.23) & & & & & & \\
\hline \multirow[t]{2}{*}{ In-kind Treatment } & $38.60 * * *$ & $36.75^{* * *}$ & $43.23 * * *$ & $30.87 * * *$ & & & & & & \\
\hline & $(11.21)$ & $(10.67)$ & $(12.31)$ & $(10.73)$ & & & & & & \\
\hline \multirow[t]{2}{*}{ Cash Treatment*Female } & & & & & 5.21 & 5.17 & 1.22 & -2.30 & 5.74 & 5.59 \\
\hline & & & & & $(8.47)$ & (8.54) & (9.35) & (8.77) & $(11.57)$ & $(11.62)$ \\
\hline \multirow[t]{2}{*}{ In-kind Treatment*Female } & & & & & $35.75^{* *}$ & $37.65 * *$ & $35.61 * * *$ & $32.87 * *$ & $47.35 * *$ & $49.92 * *$ \\
\hline & & & & & $(14.94)$ & $(14.94)$ & $(13.56)$ & $(13.21)$ & $(21.35)$ & $(21.44)$ \\
\hline \multirow[t]{2}{*}{ Cash Treatment*Male } & & & & & 28.99 & 16.81 & 8.74 & 5.13 & $44.79 * *$ & $34.17 * *$ \\
\hline & & & & & $(17.68)$ & $(13.25)$ & (31.58) & (16.10) & $(19.42)$ & $(15.51)$ \\
\hline \multirow[t]{2}{*}{ In-kind Treatment*Male } & & & & & $43.38 * *$ & $35.45^{* *}$ & $55.15^{* *}$ & 27.83 & $60.33 * * *$ & $50.61 * * *$ \\
\hline & & & & & $(16.80)$ & $(14.04)$ & $(23.06)$ & $(18.15)$ & $(19.76)$ & $(17.66)$ \\
\hline \multirow[t]{2}{*}{ Constant } & $119.69 * * *$ & $102.19 * * *$ & $120.34 * * *$ & $103.05^{* * *}$ & $119.70 * * *$ & $102.20 * * *$ & $120.37 * * *$ & $103.05 * * *$ & $99.47 * * *$ & $94.92 * * *$ \\
\hline & (8.84) & $(4.40)$ & $(7.37)$ & (3.71) & $(8.85)$ & (4.39) & (7.38) & (3.70) & (5.95) & $(5.50)$ \\
\hline Baseline trimming & No & Yes & No & Yes & No & Yes & No & Yes & No & Yes \\
\hline Waves & All & All & All & All & All & All & All & All & 5 and 6 & 5 and 6 \\
\hline Observations & 4354 & 4203 & 4354 & 4203 & 4354 & 4203 & 4354 & 4203 & 1392 & 1344 \\
\hline Number of firms & 792 & 764 & 792 & 764 & 792 & 764 & 792 & 764 & 736 & 710 \\
\hline \multicolumn{11}{|l|}{ P-values for testing: } \\
\hline Cash $=$ In-kind & 0.0668 & 0.0306 & 0.0128 & 0.0156 & & & & & & \\
\hline Cash $=$ In-kind for Females & & & & & 0.0725 & 0.0565 & 0.0205 & 0.0187 & 0.0736 & 0.058 \\
\hline Cash = In-kind for Males & & & & & 0.4873 & 0.2998 & 0.1486 & 0.3051 & 0.5164 & 0.4207 \\
\hline Cash Male = Cash Female & & & & & 0.2254 & 0.4604 & 0.8196 & 0.6854 & 0.0845 & 0.1406 \\
\hline In-kind Male = In-kind Female & & & & & 0.7346 & 0.9145 & 0.4653 & 0.8224 & 0.6555 & 0.9804 \\
\hline
\end{tabular}

Notes:

All estimation includes wave effects, which vary by gender in columns 5 on. Standard errors in parentheses, clustered at the firm level.

Trimmed specifications trim out matched quadruplets which have at least one firm with profits above 1500 cedis per month in wave 1 or 2

OLS estimation includes dummies for the matched quadruplets.

$*, * *$ and $* * *$ denote significant at the $10 \%, 5 \%$ and $1 \%$ levels. 
Table 4: Treatment Heterogeneity by Randomization Strata

Dependent Variable: Real Monthly Profits (Cedi)

\begin{tabular}{|c|c|c|c|c|c|c|c|c|}
\hline & (1) & (2) & (3) & (4) & (5) & (6) & (7) & (8) \\
\hline & OLS & $\mathrm{FE}$ & OLS & FE & OLS & FE & OLS & $\mathrm{FE}$ \\
\hline $\begin{array}{l}\text { Interaction Category A } \\
\text { Interaction Category B }\end{array}$ & \multicolumn{2}{|c|}{$\begin{array}{l}\text { Single-Sex Industry } \\
\text { Mixed Industry }\end{array}$} & \multicolumn{2}{|c|}{$\begin{array}{l}\text { Low Capture } \\
\text { High Capture }\end{array}$} & \multicolumn{2}{|c|}{$\begin{array}{l}\text { Low Capital } \\
\text { High Capital }\end{array}$} & \multicolumn{2}{|c|}{$\begin{array}{l}\text { Low Profits } \\
\text { High Profits }\end{array}$} \\
\hline \multicolumn{9}{|l|}{ Panel A: Females } \\
\hline Cash Treatment*Category A & $\begin{array}{c}9.62 \\
(10.08)\end{array}$ & $\begin{array}{c}-6.87 \\
(10.57)\end{array}$ & $\begin{array}{c}2.12 \\
(12.40)\end{array}$ & $\begin{array}{c}-8.53 \\
(13.55)\end{array}$ & $\begin{array}{c}3.13 \\
(10.62)\end{array}$ & $\begin{array}{l}-11.25 \\
(11.75)\end{array}$ & $\begin{array}{c}3.29 \\
(7.15)\end{array}$ & $\begin{array}{l}-8.58 \\
(9.65)\end{array}$ \\
\hline Cash Treatment*Category B & $\begin{array}{c}1.44 \\
(13.37)\end{array}$ & $\begin{array}{c}1.78 \\
(13.47)\end{array}$ & $\begin{array}{c}7.89 \\
(12.00)\end{array}$ & $\begin{array}{c}4.49 \\
(11.35)\end{array}$ & $\begin{array}{c}8.29 \\
(14.05)\end{array}$ & $\begin{array}{c}8.98 \\
(13.06)\end{array}$ & $\begin{array}{c}6.83 \\
(20.59)\end{array}$ & $\begin{array}{c}6.81 \\
(17.01)\end{array}$ \\
\hline In-kind Treatment*Category A & $\begin{array}{l}26.37 * \\
(14.31)\end{array}$ & $\begin{array}{c}25.39 \\
(17.03)\end{array}$ & $\begin{array}{c}28.30 \\
(23.00)\end{array}$ & $\begin{array}{c}35.41 \\
(24.07)\end{array}$ & $\begin{array}{c}15.96 \\
(10.77)\end{array}$ & $\begin{array}{c}14.25 \\
(10.41)\end{array}$ & $\begin{array}{c}2.21 \\
(6.97)\end{array}$ & $\begin{array}{c}4.58 \\
(7.52)\end{array}$ \\
\hline In-kind Treatment*Category B & $\begin{array}{l}48.26 * \\
(25.60)\end{array}$ & $\begin{array}{l}39.77^{* *} \\
(19.94)\end{array}$ & $\begin{array}{c}46.66 * * * \\
(14.15)\end{array}$ & $\begin{array}{l}31.06 * * \\
(12.50)\end{array}$ & $\begin{array}{l}65.06 * * \\
(30.21)\end{array}$ & $\begin{array}{l}55.67^{* *} \\
(26.19)\end{array}$ & $\begin{array}{c}96.18 * * * \\
(36.95)\end{array}$ & $\begin{array}{l}76.53^{* *} \\
(30.69)\end{array}$ \\
\hline Number of Observations & 2604 & 2604 & 2604 & 2604 & 2604 & 2604 & 2604 & 2604 \\
\hline $\begin{array}{l}\text { Number of Firms } \\
\text { P-values for testing: }\end{array}$ & 474 & 474 & 474 & 474 & 474 & 474 & 474 & 474 \\
\hline Cash Treatments equal & 0.625 & 0.614 & 0.740 & 0.462 & 0.771 & 0.250 & 0.871 & 0.432 \\
\hline In-kind Treatments equal & 0.456 & 0.584 & 0.457 & 0.873 & 0.124 & 0.142 & 0.013 & 0.023 \\
\hline Cash $=$ In-kind & 0.156 & 0.058 & 0.056 & 0.061 & 0.155 & 0.051 & 0.119 & 0.056 \\
\hline Panel B: Males & & & & & & & & \\
\hline Cash Treatment*Category A & $\begin{array}{c}-2.82 \\
(16.42)\end{array}$ & $\begin{array}{c}-5.75 \\
(21.54)\end{array}$ & $\begin{array}{c}-0.06 \\
(19.55)\end{array}$ & $\begin{array}{c}10.72 \\
(23.92)\end{array}$ & $\begin{array}{c}0.68 \\
(18.06)\end{array}$ & $\begin{array}{c}-0.72 \\
(20.14)\end{array}$ & $\begin{array}{c}17.23 \\
(12.99)\end{array}$ & $\begin{array}{c}-1.50 \\
(12.76)\end{array}$ \\
\hline Cash Treatment*Category B & $\begin{array}{l}36.60 * \\
(20.25)\end{array}$ & $\begin{array}{c}17.00 \\
(23.63)\end{array}$ & $\begin{array}{c}25.13 \\
(17.36)\end{array}$ & $\begin{array}{c}0.77 \\
(21.00)\end{array}$ & $\begin{array}{c}30.16 \\
(18.83)\end{array}$ & $\begin{array}{c}8.66 \\
(24.00)\end{array}$ & $\begin{array}{c}15.43 \\
(22.96)\end{array}$ & $\begin{array}{c}9.50 \\
(27.99)\end{array}$ \\
\hline In-kind Treatment* Category A & $\begin{array}{l}44.85^{* *} \\
(21.72)\end{array}$ & $\begin{array}{c}23.47 \\
(31.46)\end{array}$ & $\begin{array}{c}43.56 \\
(27.06)\end{array}$ & $\begin{array}{c}58.33 \\
(35.74)\end{array}$ & $\begin{array}{c}46.55^{* *} \\
(19.24)\end{array}$ & $\begin{array}{c}26.33 \\
(25.52)\end{array}$ & $\begin{array}{l}35.08^{*} \\
(18.00)\end{array}$ & $\begin{array}{c}32.20 \\
(23.07)\end{array}$ \\
\hline In-kind Treatment*Category B & $\begin{array}{c}28.55 \\
(18.54)\end{array}$ & $\begin{array}{c}33.69 \\
(20.66)\end{array}$ & $\begin{array}{l}30.49 * \\
(15.76)\end{array}$ & $\begin{array}{c}8.94 \\
(19.42)\end{array}$ & $\begin{array}{c}25.78 \\
(20.31)\end{array}$ & $\begin{array}{c}28.51 \\
(25.59)\end{array}$ & $\begin{array}{c}34.88 \\
(21.57)\end{array}$ & $\begin{array}{c}21.99 \\
(27.48)\end{array}$ \\
\hline Observations & 1599 & 1599 & 1599 & 1599 & 1599 & 1599 & 1599 & 1599 \\
\hline $\begin{array}{l}\text { Number of Firms } \\
\text { P-values for testing: }\end{array}$ & 290 & 290 & 290 & 290 & 290 & 290 & 290 & 290 \\
\hline Cash Treatments equal & 0.132 & 0.477 & 0.337 & 0.755 & 0.260 & 0.765 & 0.946 & 0.721 \\
\hline In-kind Treatments equal & 0.569 & 0.786 & 0.677 & 0.226 & 0.458 & 0.952 & 0.994 & 0.776 \\
\hline Cash=In-kind & 0.151 & 0.596 & 0.312 & 0.349 & 0.171 & 0.509 & 0.563 & 0.417 \\
\hline
\end{tabular}

Notes:

All estimation includes wave effects which vary by category. Standard errors in parentheses, clustered at the firm level. Trimmed sample used. OLS estimation includes dummies for the matched quadruplets.

$*, * *$ and $* * *$ denote significant at the $10 \%, 5 \%$ and $1 \%$ levels. 


\begin{tabular}{|c|c|c|c|c|c|c|c|c|c|c|}
\hline & $\begin{array}{l}\text { Capital } \\
\text { Stock } \\
\text { FE }\end{array}$ & $\begin{array}{l}\text { Truncated } \\
\text { Capital } \\
\text { Stock } \\
\text { FE }\end{array}$ & $\begin{array}{c}\text { Made a } \\
\text { Transfer } \\
\text { Out } \\
\text { OLS }\end{array}$ & $\begin{array}{c}\text { Amount } \\
\text { Transferred } \\
\text { Out } \\
\text { OLS }\end{array}$ & $\begin{array}{l}\text { Weekly } \\
\text { Food } \\
\text { Spending } \\
\text { FE }\end{array}$ & $\begin{array}{l}\text { Quarterly } \\
\text { Clothing } \\
\text { Spending } \\
\text { FE }\end{array}$ & $\begin{array}{c}\text { Quarterly } \\
\text { Health \& } \\
\text { Education } \\
\text { Spending } \\
\text { FE }\end{array}$ & $\begin{array}{c}\text { Quarterly } \\
\text { Ceremonies } \\
\text { Spending } \\
\text { FE }\end{array}$ & $\begin{array}{c}\text { Total } \\
\text { Quarterly } \\
\text { Spending } \\
\text { FE }\end{array}$ & $\begin{array}{c}\text { Log } \\
\text { Quarterly } \\
\text { Spending } \\
\text { FE }\end{array}$ \\
\hline \multicolumn{11}{|l|}{ Panel A: Males and Females } \\
\hline Cash Treatment*Female & $\begin{array}{c}82.61 \\
(72.01)\end{array}$ & $\begin{array}{c}49.17 \\
(37.27)\end{array}$ & $\begin{array}{l}0.05 * \\
(0.03)\end{array}$ & $\begin{array}{c}8.05^{* *} \\
(3.46)\end{array}$ & $\begin{array}{c}3.81 \\
(2.44)\end{array}$ & $\begin{array}{c}3.38 \\
(3.90)\end{array}$ & $\begin{array}{c}-1.05 \\
(13.42)\end{array}$ & $\begin{array}{c}1.39 \\
(3.17)\end{array}$ & $\begin{array}{c}120.54 * * * \\
(45.61)\end{array}$ & $\begin{array}{l}0.08 * \\
(0.04)\end{array}$ \\
\hline In-kind Treatment*Female & $\begin{array}{c}135.34 * * \\
(65.55)\end{array}$ & $\begin{array}{c}120.24 * * * \\
(34.51)\end{array}$ & $\begin{array}{c}0.02 \\
(0.03)\end{array}$ & $\begin{array}{c}1.76 \\
(2.92)\end{array}$ & $\begin{array}{l}-0.07 \\
(2.60)\end{array}$ & $\begin{array}{l}-0.50 \\
(4.39)\end{array}$ & $\begin{array}{c}-6.08 \\
(13.03)\end{array}$ & $\begin{array}{c}2.33 \\
(3.46)\end{array}$ & $\begin{array}{c}45.36 \\
(44.36)\end{array}$ & $\begin{array}{l}-0.02 \\
(0.04)\end{array}$ \\
\hline Cash Treatment*Male & $\begin{array}{c}31.36 \\
(70.33)\end{array}$ & $\begin{array}{c}2.21 \\
(61.10)\end{array}$ & $\begin{array}{c}0.03 \\
(0.04)\end{array}$ & $\begin{array}{l}-4.06 \\
(3.93)\end{array}$ & $\begin{array}{c}3.93 \\
(3.12)\end{array}$ & $\begin{array}{l}9.52^{*} \\
(5.08)\end{array}$ & $\begin{array}{c}0.98 \\
(11.26)\end{array}$ & $\begin{array}{c}3.27 \\
(3.92)\end{array}$ & $\begin{array}{c}63.94 \\
(50.82)\end{array}$ & $\begin{array}{c}0.03 \\
(0.04)\end{array}$ \\
\hline In-kind Treatment*Male & $\begin{array}{c}157.71 \\
(102.12)\end{array}$ & $\begin{array}{c}83.74 \\
(69.85)\end{array}$ & $\begin{array}{c}0.01 \\
(0.04)\end{array}$ & $\begin{array}{l}-6.01 \\
(3.95)\end{array}$ & $\begin{array}{l}-2.82 \\
(3.42)\end{array}$ & $\begin{array}{c}3.63 \\
(5.83)\end{array}$ & $\begin{array}{c}-0.85 \\
(23.28)\end{array}$ & $\begin{array}{c}4.36 \\
(5.20)\end{array}$ & $\begin{array}{c}20.95 \\
(65.12)\end{array}$ & $\begin{array}{l}-0.01 \\
(0.05)\end{array}$ \\
\hline Number of Observations & 4256 & 4256 & 2033 & 2203 & 4268 & 3911 & 3713 & 4286 & 4495 & 4299 \\
\hline Number of Firms & 765 & 765 & 722 & 722 & 765 & 761 & 753 & 765 & 765 & 765 \\
\hline P-values testing: & & & & & & & & & & \\
\hline Cash $=$ In-kind Females & 0.573 & 0.107 & 0.294 & 0.137 & 0.198 & 0.478 & 0.776 & 0.817 & 0.172 & 0.054 \\
\hline Cash $=\ln$-kind Males & 0.212 & 0.291 & 0.693 & 0.630 & 0.111 & 0.428 & 0.942 & 0.856 & 0.573 & 0.611 \\
\hline Panel B: Female Sub-sample & & & & & & & & & & \\
\hline Cash Treatment*Low Profits & $\begin{array}{c}-6.77 \\
(29.67)\end{array}$ & $\begin{array}{c}-6.78 \\
(29.69)\end{array}$ & $\begin{array}{c}0.07 * * \\
(0.03)\end{array}$ & $\begin{array}{c}6.13 * * \\
(2.80)\end{array}$ & $\begin{array}{c}7.26^{* *} \\
(3.32)\end{array}$ & $\begin{array}{c}4.66 \\
(4.24)\end{array}$ & $\begin{array}{c}15.39 \\
(18.93)\end{array}$ & $\begin{array}{c}2.94 \\
(4.11)\end{array}$ & $\begin{array}{c}197.84 * * * \\
(58.16)\end{array}$ & $\begin{array}{c}0.16 * * \\
(0.06)\end{array}$ \\
\hline Cash Treatment*High Profits & $\begin{array}{c}238.00 \\
(185.23)\end{array}$ & $\begin{array}{c}145.84^{*} \\
(85.70)\end{array}$ & $\begin{array}{c}0.02 \\
(0.04)\end{array}$ & $\begin{array}{l}11.54 \\
(8.35)\end{array}$ & $\begin{array}{l}-2.13 \\
(4.27)\end{array}$ & $\begin{array}{c}8.29 \\
(8.08)\end{array}$ & $\begin{array}{l}-25.71 \\
(18.79)\end{array}$ & $\begin{array}{l}-8.05 \\
(5.48)\end{array}$ & $\begin{array}{l}-53.38 \\
(81.92)\end{array}$ & $\begin{array}{l}-0.07 \\
(0.06)\end{array}$ \\
\hline In-kind Treatment*Low Profits & $\begin{array}{c}59.17^{* *} \\
(28.45)\end{array}$ & $\begin{array}{c}59.17^{* *} \\
(28.46)\end{array}$ & $\begin{array}{c}0.01 \\
(0.03)\end{array}$ & $\begin{array}{l}-0.40 \\
(2.02)\end{array}$ & $\begin{array}{c}1.11 \\
(3.93)\end{array}$ & $\begin{array}{c}4.10 \\
(5.20)\end{array}$ & $\begin{array}{c}3.83 \\
(18.81)\end{array}$ & $\begin{array}{l}-2.38 \\
(3.09)\end{array}$ & $\begin{array}{c}32.92 \\
(63.98)\end{array}$ & $\begin{array}{l}-0.02 \\
(0.06)\end{array}$ \\
\hline In-kind Treatment*High Profits & $\begin{array}{c}262.60 \\
(166.25)\end{array}$ & $\begin{array}{c}223.24 * * * \\
(77.66)\end{array}$ & $\begin{array}{c}0.03 \\
(0.05)\end{array}$ & $\begin{array}{c}5.12 \\
(6.76)\end{array}$ & $\begin{array}{l}-1.99 \\
(3.94)\end{array}$ & $\begin{array}{l}-2.43 \\
(8.01)\end{array}$ & $\begin{array}{l}-18.48 \\
(17.24)\end{array}$ & $\begin{array}{c}3.11 \\
(7.79)\end{array}$ & $\begin{array}{c}18.07 \\
(68.53)\end{array}$ & $\begin{array}{l}-0.04 \\
(0.06)\end{array}$ \\
\hline Number of Observations & 2654 & 2654 & 1260 & 1260 & 2657 & 2440 & 2323 & 2666 & 2790 & 2670 \\
\hline Number of Firms & 475 & 475 & 446 & 446 & 475 & 475 & 468 & 475 & 475 & 475 \\
\hline P-values testing: & & & & & & & & & & \\
\hline Cash Treatments Equal & 0.193 & 0.093 & 0.351 & 0.540 & 0.083 & 0.691 & 0.124 & 0.109 & 0.013 & 0.007 \\
\hline In-kind Treatments Equal & 0.228 & 0.048 & 0.769 & 0.435 & 0.578 & 0.494 & 0.382 & 0.513 & 0.874 & 0.827 \\
\hline
\end{tabular}

\section{Notes:}

All expenditure data truncated at the 99.5th percentile of the data.

All estimation includes wave effects which vary by gender, and by category in panel B. Standard errors in parentheses, clustered at the firm level.

High and Low profits refers to groups defined on pre-treatment profits.

Trimmed sample used. OLS estimation includes dummies for the matched quadruplets.

$*, * *$ and ${ }^{* * *}$ denote significant at the $10 \%, 5 \%$ and $1 \%$ levels. 


\begin{tabular}{|c|c|c|c|c|}
\hline & Men & $\begin{array}{c}\text { Low } \\
\text { Initial Profit } \\
\text { Women }\end{array}$ & $\begin{array}{c}\text { High } \\
\text { Initial Profits } \\
\text { Women } \\
\end{array}$ & $\begin{array}{c}\text { Sri Lankan } \\
\text { Women }\end{array}$ \\
\hline \multicolumn{5}{|l|}{ Monthly profits in January $2009^{a}$} \\
\hline Mean & 130 & 38 & $173 * * *$ & 28 \\
\hline Median & 91 & 37 & $137 * * *$ & 20 \\
\hline \multicolumn{5}{|l|}{ Monthly sales in January 2009} \\
\hline Mean & 502 & 187 & $822 * * *$ & 87 \\
\hline Median & 240 & 120 & $500 * * *$ & 50 \\
\hline \multicolumn{5}{|l|}{ Total Capital Stock in January 2009} \\
\hline Mean & 611 & 251 & $456 * * *$ & 207 \\
\hline Median & 255 & 102 & $162 * * *$ & 100 \\
\hline Age of Owner & 35.4 & 35.9 & 37.0 & 41.1 \\
\hline Age of Firm & 9.1 & 6.0 & $7.4^{* *}$ & 9.5 \\
\hline Ever had a formal loan & 0.07 & 0.08 & $0.15^{* *}$ & 0.23 \\
\hline Keeps accounts & 0.45 & 0.31 & $0.44^{* *}$ & 0.29 \\
\hline Years of Education & 10.04 & 7.80 & $8.63^{* *}$ & 9.44 \\
\hline Digitspan Recall & 5.70 & 4.59 & 4.80 & 5.68 \\
\hline Chose sector as it had low capital requirements & 0.17 & 0.40 & $0.32 *$ & n.a. \\
\hline Chose sector for profit potential & 0.18 & 0.11 & $0.18^{* *}$ & n.a. \\
\hline Willingness to Take Risks & 5.64 & 4.28 & 4.40 & 6.08 \\
\hline Save regularly & 0.71 & 0.62 & $0.73 * *$ & 0.67 \\
\hline Household Asset index & 0.29 & -0.40 & $0.14 * * *$ & n.a. \\
\hline Household has a Cellphone & 0.94 & 0.88 & 0.91 & 0.22 \\
\hline Sample Size & 290 & 296 & 179 & 190 \\
\hline
\end{tabular}

Notes:

Means shown unless indicated otherwise. Trimmed subsample used.

$*, * *$, and $* * *$ indicate high profit women statistically different from the low profit women at the $10 \%, 5 \%$ and $1 \%$ levels respectively.

a. Figures for Sri Lanka are reported as of March 2005 Sri Lankan baseline, converted at an approximate exchange rate of 100 Sri Lankan rupees to 1 cedi.

n.a. indicates not available in Sri Lankan data. 
Table 7: Heterogeneity according to self-control

Dependent variable: Real profits

\begin{tabular}{|c|c|c|c|c|c|c|c|c|c|}
\hline Interaction Category: & $\begin{array}{l}\text { Used a } \\
\text { Susu at } \\
\text { Baseline }\end{array}$ & $\begin{array}{l}\text { Said they } \\
\text { Save } \\
\text { regularly }\end{array}$ & $\begin{array}{l}\text { Discount } \\
\text { rate above } \\
\text { median }\end{array}$ & $\begin{array}{l}\text { Hyperbolic } \\
\text { Discounter }\end{array}$ & $\begin{array}{c}\text { Lacks } \\
\text { Self-control }\end{array}$ & $\begin{array}{l}\text { Says there is } \\
\text { pressure to } \\
\text { share with hh }\end{array}$ & $\begin{array}{c}\text { Can spend } \\
\text { freely without } \\
\text { spouse }\end{array}$ & $\begin{array}{l}\text { Household } \\
\text { Size }\end{array}$ & $\begin{array}{l}\text { Number of } \\
\text { Siblings } \\
\text { in Area }\end{array}$ \\
\hline \multicolumn{10}{|c|}{ Panel A: Pooling Treatment Effects across Gender } \\
\hline Cash Treatment & $\begin{array}{l}-5.117 \\
(11.05)\end{array}$ & $\begin{array}{c}-34.97 * * \\
(14.58)\end{array}$ & $\begin{array}{c}13.26 \\
(13.92)\end{array}$ & $\begin{array}{c}6.219 \\
(10.33)\end{array}$ & $\begin{array}{c}2.768 \\
(8.579)\end{array}$ & $\begin{array}{c}1.187 \\
(9.886)\end{array}$ & $\begin{array}{l}-8.618 \\
(18.29)\end{array}$ & $\begin{array}{c}2.191 \\
(8.350)\end{array}$ & $\begin{array}{c}0.414 \\
(8.624)\end{array}$ \\
\hline In-kind Treatment & $\begin{array}{c}25.24 \\
(15.34)\end{array}$ & $\begin{array}{l}-4.260 \\
(9.341)\end{array}$ & $\begin{array}{c}13.97 \\
(11.20)\end{array}$ & $\begin{array}{c}40.35^{* * *} \\
(14.49)\end{array}$ & $\begin{array}{c}29.80 * * * \\
(10.81)\end{array}$ & $\begin{array}{l}31.54 * * \\
(12.49)\end{array}$ & $\begin{array}{c}8.972 \\
(13.33)\end{array}$ & $\begin{array}{c}28.79 * * * \\
(10.62)\end{array}$ & $\begin{array}{c}25.61 * * \\
(10.40)\end{array}$ \\
\hline Cash Treatment * Interaction & $\begin{array}{c}14.54 \\
(16.70)\end{array}$ & $\begin{array}{c}50.95^{* * *} \\
(17.69)\end{array}$ & $\begin{array}{l}-21.97 \\
(17.15)\end{array}$ & $\begin{array}{l}-18.70 \\
(16.82)\end{array}$ & $\begin{array}{c}-16.13^{* *} \\
(8.102)\end{array}$ & $\begin{array}{l}-0.705 \\
(17.82)\end{array}$ & $\begin{array}{c}13.44 \\
(22.54)\end{array}$ & $\begin{array}{c}5.937 \\
(4.238)\end{array}$ & $\begin{array}{c}2.166 \\
(3.284)\end{array}$ \\
\hline In-kind Treatment *Interaction & $\begin{array}{c}10.35 \\
(20.80)\end{array}$ & $\begin{array}{c}49.41^{* * *} \\
(17.91)\end{array}$ & $\begin{array}{c}31.00 \\
(20.66)\end{array}$ & $\begin{array}{c}-38.88 * * \\
(18.09)\end{array}$ & $\begin{array}{l}-6.587 \\
(6.273)\end{array}$ & $\begin{array}{l}-23.61 \\
(20.36)\end{array}$ & $\begin{array}{c}20.68 \\
(20.09)\end{array}$ & $\begin{array}{c}0.451 \\
(5.022)\end{array}$ & $\begin{array}{l}6.469 * \\
(3.835)\end{array}$ \\
\hline p-value for testing interactions jointly zero & 0.6355 & 0.001 & 0.1024 & 0.0708 & 0.0983 & 0.501 & 0.535 & 0.371 & 0.198 \\
\hline Observations & 4,170 & 4,157 & 4,169 & 4,157 & 4,145 & 3,880 & 2,702 & 4,169 & 3,750 \\
\hline Number of firms & 758 & 755 & 758 & 755 & 753 & 675 & 490 & 757 & 652 \\
\hline Panel B: Females Sub-sample only & & & & & & & & & \\
\hline Cash Treatment & $\begin{array}{l}-8.313 \\
(12.94)\end{array}$ & $\begin{array}{l}-20.90 \\
(17.44)\end{array}$ & $\begin{array}{c}9.207 \\
(15.23)\end{array}$ & $\begin{array}{c}0.955 \\
(10.69)\end{array}$ & $\begin{array}{l}-0.608 \\
(9.100)\end{array}$ & $\begin{array}{l}-3.369 \\
(10.76)\end{array}$ & $\begin{array}{c}0.710 \\
(19.53)\end{array}$ & $\begin{array}{l}-3.461 \\
(8.711)\end{array}$ & $\begin{array}{l}0.0197 \\
(9.261)\end{array}$ \\
\hline In-kind Treatment & $\begin{array}{c}24.79 \\
(21.96)\end{array}$ & $\begin{array}{l}-2.700 \\
(8.508)\end{array}$ & $\begin{array}{c}12.62 \\
(11.47)\end{array}$ & $\begin{array}{c}41.12^{* *} \\
(17.56)\end{array}$ & $\begin{array}{c}31.20 * * \\
(13.04)\end{array}$ & $\begin{array}{c}35.56 * * \\
(17.04)\end{array}$ & $\begin{array}{l}-4.982 \\
(12.88)\end{array}$ & $\begin{array}{c}30.52 * * \\
(13.40)\end{array}$ & $\begin{array}{c}33.84 * * \\
(13.80)\end{array}$ \\
\hline Cash Treatment * Interaction & $\begin{array}{c}12.37 \\
(17.51)\end{array}$ & $\begin{array}{c}28.15 \\
(20.15)\end{array}$ & $\begin{array}{l}-19.78 \\
(18.47)\end{array}$ & $\begin{array}{l}-11.43 \\
(18.97)\end{array}$ & $\begin{array}{l}-11.65 \\
(7.963)\end{array}$ & $\begin{array}{c}16.55 \\
(16.63)\end{array}$ & $\begin{array}{c}2.671 \\
(24.14)\end{array}$ & $\begin{array}{l}10.49 * * \\
(4.602)\end{array}$ & $\begin{array}{c}5.174 * * \\
(2.092)\end{array}$ \\
\hline In-kind Treatment *Interaction & $\begin{array}{c}14.44 \\
(27.10)\end{array}$ & $\begin{array}{c}50.76 * * \\
(20.86)\end{array}$ & $\begin{array}{c}38.26 \\
(25.00)\end{array}$ & $\begin{array}{c}-34.74 \\
(23.17)\end{array}$ & $\begin{array}{l}-3.526 \\
(7.445)\end{array}$ & $\begin{array}{l}-10.42 \\
(23.13)\end{array}$ & $\begin{array}{c}42.57 * * \\
(17.84)\end{array}$ & $\begin{array}{l}-1.392 \\
(6.528)\end{array}$ & $\begin{array}{c}2.144 \\
(2.694)\end{array}$ \\
\hline $\mathrm{p}$-value for testing interactions jointly zero & 0.704 & 0.033 & 0.139 & 0.297 & 0.318 & 0.479 & 0.051 & 0.064 & 0.045 \\
\hline Observations & 2,588 & 2,586 & 2,587 & 2,580 & 2,574 & 2,398 & 1,730 & 2,592 & 2,375 \\
\hline Number of firms & 471 & 470 & 471 & 469 & 468 & 418 & 312 & 471 & 414 \\
\hline
\end{tabular}

Notes: Results from Fixed effects estimation on trimmed sample.

$*, * *$ and ${ }^{* * *}$ denote significant at the $10 \%, 5 \%$ and $1 \%$ levels.

All regressions include wave effects which vary with the interaction. 
Table 8. Dependent Variable: Real Profits

\begin{tabular}{|c|c|c|c|c|c|c|c|c|c|c|c|c|c|c|}
\hline \multirow[t]{3}{*}{ Interaction is: } & \multicolumn{2}{|c|}{$\begin{array}{c}\text { Whether they are } \\
\text { married }\end{array}$} & \multicolumn{2}{|c|}{$\begin{array}{c}\text { Share of assets } \\
\text { brought to marriage }\end{array}$} & \multicolumn{2}{|c|}{$\begin{array}{c}\text { Difference in education } \\
\text { between spouses }\end{array}$} & \multicolumn{2}{|c|}{$\begin{array}{l}\text { Difference in age } \\
\text { between spouses }\end{array}$} & \multicolumn{2}{|c|}{$\begin{array}{l}\text { Spend income } \\
\text { without consent }\end{array}$} & \multicolumn{2}{|c|}{$\begin{array}{c}\text { Baseline profits } \\
\text { as share of income }\end{array}$} & \multicolumn{2}{|c|}{$\begin{array}{c}\text { Baseline profits } \\
\text { as share of consumption }\end{array}$} \\
\hline & (1) & (2) & (3) & (4) & (5) & (6) & (7) & (8) & (9) & $(10)$ & (11) & $(12)$ & (13) & (14) \\
\hline & Female & Male & Female & Male & Female & Male & Female & Male & Female & Male & Female & Male & Female & Male \\
\hline Cash Treatment & $\begin{array}{l}-9.640 \\
(12.84)\end{array}$ & $\begin{array}{c}16.78 \\
(24.73)\end{array}$ & $\begin{array}{c}20.54 \\
(17.50)\end{array}$ & $\begin{array}{c}1.823 \\
(60.36)\end{array}$ & $\begin{array}{c}18.69 \\
(17.00)\end{array}$ & $\begin{array}{c}2.177 \\
(30.95)\end{array}$ & $\begin{array}{l}-0.0262 \\
(25.64)\end{array}$ & $\begin{array}{l}-3.651 \\
(33.45)\end{array}$ & $\begin{array}{c}0.710 \\
(19.53)\end{array}$ & $\begin{array}{l}-47.59 \\
(47.88)\end{array}$ & $\begin{array}{l}-8.692 \\
(20.83)\end{array}$ & $\begin{array}{l}-25.43 \\
(27.64)\end{array}$ & $\begin{array}{l}0.0859 \\
(13.84)\end{array}$ & $\begin{array}{c}7.697 \\
(21.89)\end{array}$ \\
\hline In-kind Treatment & $\begin{array}{c}40.89 \\
(33.71)\end{array}$ & $\begin{array}{c}34.99 \\
(23.63)\end{array}$ & $\begin{array}{l}49.01^{*} \\
(27.46)\end{array}$ & $\begin{array}{c}23.79 \\
(63.60)\end{array}$ & $\begin{array}{l}40.52^{* *} \\
(17.86)\end{array}$ & $\begin{array}{c}20.61 \\
(60.32)\end{array}$ & $\begin{array}{c}43.21 \\
(27.16)\end{array}$ & $\begin{array}{c}26.00 \\
(28.63)\end{array}$ & $\begin{array}{l}-4.982 \\
(12.88)\end{array}$ & $\begin{array}{c}29.59 \\
(25.65)\end{array}$ & $\begin{array}{c}32.56 \\
(23.58)\end{array}$ & $\begin{array}{c}147.1 \\
(104.1)\end{array}$ & $\begin{array}{l}64.50^{*} \\
(33.17)\end{array}$ & $\begin{array}{c}24.56 \\
(23.21)\end{array}$ \\
\hline Cash*Interaction & $\begin{array}{c}11.56 \\
(17.18)\end{array}$ & $\begin{array}{l}-17.11 \\
(33.14)\end{array}$ & $\begin{array}{l}-6.289 \\
(27.52)\end{array}$ & $\begin{array}{l}-14.47 \\
(77.95)\end{array}$ & $\begin{array}{c}0.752 \\
(2.474)\end{array}$ & $\begin{array}{c}1.820 \\
(5.634)\end{array}$ & $\begin{array}{l}-0.162 \\
(2.339)\end{array}$ & $\begin{array}{l}0.0687 \\
(6.121)\end{array}$ & $\begin{array}{c}2.671 \\
(24.14)\end{array}$ & $\begin{array}{c}55.74 \\
(54.47)\end{array}$ & $\begin{array}{c}8.387 \\
(24.37)\end{array}$ & $\begin{array}{c}34.63 \\
(39.97)\end{array}$ & $\begin{array}{l}-2.005 \\
(17.24)\end{array}$ & $\begin{array}{c}16.82 \\
(26.29)\end{array}$ \\
\hline In-kind*Interaction & $\begin{array}{l}-11.91 \\
(35.28)\end{array}$ & $\begin{array}{l}-12.19 \\
(34.08)\end{array}$ & $\begin{array}{l}-16.09 \\
(39.86)\end{array}$ & $\begin{array}{l}-6.332 \\
(84.32)\end{array}$ & $\begin{array}{c}0.101 \\
(3.249)\end{array}$ & $\begin{array}{c}6.441 \\
(9.761)\end{array}$ & $\begin{array}{l}0.0207 \\
(2.550)\end{array}$ & $\begin{array}{l}-2.986 \\
(4.113)\end{array}$ & $\begin{array}{r}42.57^{* *} \\
(17.84)\end{array}$ & $\begin{array}{l}-13.18 \\
(43.76)\end{array}$ & $\begin{array}{l}-0.605 \\
(32.46)\end{array}$ & $\begin{array}{l}-135.2 \\
(108.0)\end{array}$ & $\begin{array}{l}-54.76 \\
(34.21)\end{array}$ & $\begin{array}{c}12.98 \\
(37.70)\end{array}$ \\
\hline Observations & 2,599 & 1,593 & 1,273 & 864 & 956 & 799 & 1,520 & 932 & 1,730 & 972 & 2,408 & 1,501 & 2,604 & 1,599 \\
\hline Number of firms & 473 & 289 & 222 & 151 & 172 & 147 & 264 & 163 & 312 & 178 & 431 & 267 & 474 & 290 \\
\hline
\end{tabular}

Robust standard errors in parentheses

$* * * p<0.01, * * p<0.05, * p<0.1$ 
Table 9: Heterogeneity according to external pressure

Dependent variable: Real profits

\begin{tabular}{|c|c|c|c|}
\hline Interaction Category: & $\begin{array}{l}\text { Household } \\
\text { Size }\end{array}$ & $\begin{array}{l}\text { Says there is } \\
\text { pressure to } \\
\text { share with hh }\end{array}$ & $\begin{array}{c}\text { Number of } \\
\text { Siblings } \\
\text { in Area }\end{array}$ \\
\hline \multicolumn{4}{|c|}{ Panel A: Pooling Treatment Effects across Gender } \\
\hline Cash Treatment & $\begin{array}{c}2.191 \\
(8.350)\end{array}$ & $\begin{array}{c}1.187 \\
(9.886)\end{array}$ & $\begin{array}{c}0.414 \\
(8.624)\end{array}$ \\
\hline In-kind Treatment & $\begin{array}{c}28.79 * * * \\
(10.62)\end{array}$ & $\begin{array}{c}31.54 * * \\
(12.49)\end{array}$ & $\begin{array}{c}25.61 * * \\
(10.40)\end{array}$ \\
\hline Cash Treatment * Interaction & $\begin{array}{c}5.937 \\
(4.238)\end{array}$ & $\begin{array}{l}-0.705 \\
(17.82)\end{array}$ & $\begin{array}{c}2.166 \\
(3.284)\end{array}$ \\
\hline In-kind Treatment *Interaction & $\begin{array}{c}0.451 \\
(5.022)\end{array}$ & $\begin{array}{l}-23.61 \\
(20.36)\end{array}$ & $\begin{array}{l}6.469 * \\
(3.835)\end{array}$ \\
\hline$p$-value for testing interactions jointly zero & 0.371 & 0.501 & 0.198 \\
\hline Observations & 4,169 & 3,880 & 3,750 \\
\hline Number of firms & 757 & 675 & 652 \\
\hline \multicolumn{4}{|l|}{ Panel B: Females Sub-sample only } \\
\hline Cash Treatment & $\begin{array}{l}-3.461 \\
(8.711)\end{array}$ & $\begin{array}{l}-3.369 \\
(10.76)\end{array}$ & $\begin{array}{l}0.0197 \\
(9.261)\end{array}$ \\
\hline In-kind Treatment & $\begin{array}{c}30.52 * * \\
(13.40)\end{array}$ & $\begin{array}{c}35.56^{* *} \\
(17.04)\end{array}$ & $\begin{array}{c}33.84 * * \\
(13.80)\end{array}$ \\
\hline Cash Treatment * Interaction & $\begin{array}{c}10.49 * * \\
(4.602)\end{array}$ & $\begin{array}{c}16.55 \\
(16.63)\end{array}$ & $\begin{array}{c}5.174 * * \\
(2.092)\end{array}$ \\
\hline In-kind Treatment *Interaction & $\begin{array}{l}-1.392 \\
(6.528)\end{array}$ & $\begin{array}{l}-10.42 \\
(23.13)\end{array}$ & $\begin{array}{c}2.144 \\
(2.694)\end{array}$ \\
\hline $\mathrm{p}$-value for testing interactions jointly zero & 0.064 & 0.479 & 0.045 \\
\hline Observations & 2,592 & 2,398 & 2,375 \\
\hline Number of firms & 471 & 418 & 414 \\
\hline
\end{tabular}

Notes: Results from Fixed effects estimation on trimmed sample.

$*, * *$ and ${ }^{* * *}$ denote significant at the $10 \%, 5 \%$ and $1 \%$ levels.

All regressions include wave effects which vary with the interaction. 
Table 10: Is self-control just proxying for external pressure

Dependent Variable: "Lack of Self-control" Index

\begin{tabular}{|c|c|c|c|c|}
\hline & $\begin{array}{c}\text { Males \& } \\
\text { Females } \\
(1)\end{array}$ & $\begin{array}{c}\text { Married } \\
\text { Males \& Females } \\
(2)\end{array}$ & $\begin{array}{c}\text { Females } \\
(3)\end{array}$ & $\begin{array}{l}\text { Married } \\
\text { Females } \\
(4)\end{array}$ \\
\hline Female & $\begin{array}{l}-0.0860 \\
(0.0885)\end{array}$ & $\begin{array}{l}-0.0969 \\
(0.110)\end{array}$ & & \\
\hline Baseline profits below the median & $\begin{array}{c}0.0954 \\
(0.0887)\end{array}$ & $\begin{array}{c}-0.00624 \\
(0.113)\end{array}$ & $\begin{array}{c}0.101 \\
(0.118)\end{array}$ & $\begin{array}{r}-0.0329 \\
(0.148)\end{array}$ \\
\hline $\begin{array}{l}\text { Says there is pressure to share extra profits } \\
\text { with other household members }\end{array}$ & $\begin{array}{l}0.0505 \\
(0.103)\end{array}$ & $\begin{array}{r}-0.0609 \\
(0.122)\end{array}$ & $\begin{array}{l}0.0359 \\
(0.138)\end{array}$ & $\begin{array}{l}-0.111 \\
(0.162)\end{array}$ \\
\hline Baseline household Size & $\begin{array}{c}0.0144 \\
(0.0226)\end{array}$ & $\begin{array}{l}0.00290 \\
(0.0305)\end{array}$ & $\begin{array}{l}-0.000428 \\
(0.0307)\end{array}$ & $\begin{array}{l}-0.0191 \\
(0.0404)\end{array}$ \\
\hline Number of Siblings in Accra/Tema & $\begin{array}{c}0.0239 \\
(0.0157)\end{array}$ & $\begin{array}{c}0.0120 \\
(0.0208)\end{array}$ & $\begin{array}{c}0.0378^{* *} \\
(0.0190)\end{array}$ & $\begin{array}{c}0.0250 \\
(0.0238)\end{array}$ \\
\hline $\begin{array}{l}\text { Agrees that whenever they have money on hand, their } \\
\text { spouse or other family members always end up requesting some. }\end{array}$ & $\begin{array}{c}0.0583 \\
(0.0989)\end{array}$ & $\begin{array}{c}0.115 \\
(0.125)\end{array}$ & $\begin{array}{l}-0.00133 \\
(0.128)\end{array}$ & $\begin{array}{l}0.0620 \\
(0.154)\end{array}$ \\
\hline $\begin{array}{l}\text { Agrees that people who do well in their business are likely to receive } \\
\text { additional requests from family and friends for money to help out }\end{array}$ & $\begin{array}{l}0.0393 \\
(0.115)\end{array}$ & $\begin{array}{l}-0.100 \\
(0.146)\end{array}$ & $\begin{array}{l}0.0916 \\
(0.145)\end{array}$ & $\begin{array}{r}-0.0605 \\
(0.184)\end{array}$ \\
\hline $\begin{array}{l}\text { Agrees that machines and equipment held in their business are a good } \\
\text { way of saving money so that others don't take it. }\end{array}$ & $\begin{array}{c}0.0303 \\
(0.0906)\end{array}$ & $\begin{array}{l}0.0507 \\
(0.113)\end{array}$ & $\begin{array}{c}-0.00774 \\
(0.115)\end{array}$ & $\begin{array}{r}-0.0186 \\
(0.143)\end{array}$ \\
\hline $\begin{array}{l}\text { At baseline spouse had compelled them to give money that they } \\
\text { didn't want to during last } 3 \text { months }\end{array}$ & & $\begin{array}{r}-0.0699 \\
(0.158)\end{array}$ & & $\begin{array}{c}0.220 \\
(0.210)\end{array}$ \\
\hline Can spend their income without consulting their spouse & & $\begin{array}{l}-0.148 \\
(0.122)\end{array}$ & & $\begin{array}{l}-0.219 \\
(0.156)\end{array}$ \\
\hline Spouse is supportive of them running a business & & $\begin{array}{l}-0.218 \\
(0.160)\end{array}$ & & $\begin{array}{l}-0.215 \\
(0.204)\end{array}$ \\
\hline Constant & $\begin{array}{c}0.00766 \\
(0.130)\end{array}$ & $\begin{array}{c}0.487 * * \\
(0.240)\end{array}$ & $\begin{array}{c}-0.0548 \\
(0.157)\end{array}$ & $\begin{array}{l}0.493^{*} \\
(0.284)\end{array}$ \\
\hline Number of Observations & 667 & 427 & 403 & 262 \\
\hline R-squared & 0.009 & 0.017 & 0.010 & 0.025 \\
\hline P-value for testing joint insignificance of all variables & 0.581 & 0.897 & 0.682 & 0.705 \\
\hline
\end{tabular}

Notes:

Coefficients are from an OLS regression of an index formed as the first principal component of using a susu, saving regularly, being a hyperbolic discounter, and having above the median discount rate on the variables listed in the table

Robust standard errors in parentheses; ${ }^{*}, * *$, and $* * *$ indicate significance at the $10 \%, 5 \%$ and $1 \%$ levels respectively 


All firms Control Cash In-kind $\begin{array}{r}\begin{array}{r}\text { P-value test } \\ \text { of equality }\end{array} \\ \hline\end{array}$

\begin{tabular}{lccccc}
\hline Didn't Answer Survey & & & & & \\
Wave 1 & 0 & 0 & 0 & 0 & 1 \\
Wave 2 & 0 & 0 & 0 & 0 & 1 \\
Wave 3 & 0.029 & 0.031 & 0.010 & 0.042 & 0.106 \\
Wave 4 & 0.073 & 0.086 & 0.068 & 0.052 & 0.303 \\
Wave 5 & 0.112 & 0.131 & 0.099 & 0.089 & 0.262 \\
Wave 6 & 0.080 & 0.102 & 0.047 & 0.068 & 0.050 \\
Any Wave & 0.166 & 0.196 & 0.131 & 0.141 & 0.070 \\
Missing profits data & & & & & \\
Wave 1 & 0.080 & 0.091 & 0.071 & 0.071 & 0.615 \\
Wave 2 & 0.016 & 0.013 & 0.025 & 0.010 & 0.477 \\
Wave 3 & 0.069 & 0.076 & 0.061 & 0.071 & 0.740 \\
Wave 4 & 0.098 & 0.123 & 0.076 & 0.071 & 0.064 \\
Wave 5 & 0.129 & 0.149 & 0.121 & 0.106 & 0.207 \\
Wave 6 & 0.114 & 0.141 & 0.086 & 0.086 & 0.059 \\
Any Wave & 0.285 & 0.329 & 0.236 & 0.246 & 0.019 \\
Ever close business & 0.064 & 0.073 & 0.063 & 0.047 & 0.463 \\
\hline Wote: Test of equalty if based & &
\end{tabular}

Note: Test of equality if based on regression of attrition on treatment group

with controls for stratification groups and robust standard errors.

\section{Appendix Table A2: Robustness of Treatment Effect to Lee Bounds}

Dependent Variable: Real Monthly Profits (Cedis)

\begin{tabular}{lcccccc}
\hline & $(1)$ & $(2)$ & $(3)$ & $(4)$ & $(5)$ & $(6)$ \\
& OLS & FE & OLS & OLS & FE & FE \\
\hline Cash Treatment*Female & 5.167 & -2.298 & 6.093 & 1.148 & -1.441 & -3.297 \\
& $(8.545)$ & $(8.768)$ & $(8.767)$ & $(7.106)$ & $(8.927)$ & $(7.226)$ \\
In-kind Treatment*Female & $37.65^{* *}$ & $32.87^{* *}$ & $40.88^{* * *}$ & 9.378 & $35.34^{* * *}$ & 11.06 \\
& $(14.94)$ & $(13.21)$ & $(15.41)$ & $(7.066)$ & $(13.59)$ & $(7.661)$ \\
Cash Treatment*Male & 16.81 & 5.132 & 21.82 & 6.218 & 9.154 & -5.718 \\
& $(13.25)$ & $(16.10)$ & $(13.28)$ & $(11.28)$ & $(16.02)$ & $(13.87)$ \\
In-kind Treatment*Male & $35.45^{* *}$ & 27.83 & $37.26^{* * *}$ & 14.71 & 28.11 & 8.421 \\
& $(14.04)$ & $(18.15)$ & $(14.07)$ & $(10.14)$ & $(18.21)$ & $(14.07)$ \\
& & & & & & \\
Lee Bounding & No & No & Upper & Lower & Upper & Lower \\
Number of Observations & & & & & & 4167 \\
Number of Firms & 4203 & 4203 & 4165 & 4167 & 4165 & 4164 \\
\hline
\end{tabular}

Notes:

All estimation includes wave effects. Standard errors in parentheses, clustered at the firm level.

Trimmed Sample used for all columns

OLS estimation includes dummies for the matched quadruplets.

$*, * *$ and $* * *$ denote significant at the $10 \%, 5 \%$ and $1 \%$ levels. 
Appendix Table A3: How does Treatment Effect Vary with Time Since Treatment?

Dependent Variable: Real Monthly Profits

\begin{tabular}{|c|c|c|c|c|c|c|c|c|}
\hline & \multicolumn{4}{|c|}{ Males and Females Pooled } & \multicolumn{2}{|c|}{ Males } & \multicolumn{2}{|c|}{ Females } \\
\hline & (1) & $(2)$ & (3) & (4) & (5) & (6) & (7) & (8) \\
\hline & OLS & OLS & FE & $\mathrm{FE}$ & OLS & FE & OLS & $\mathrm{FE}$ \\
\hline \multirow[t]{2}{*}{ Cash Treatment at 3 months } & 14.27 & 9.12 & 5.89 & 1.13 & 5.05 & -2.58 & 11.52 & 3.25 \\
\hline & $(10.26)$ & (8.01) & $(11.23)$ & (8.31) & $(15.03)$ & $(15.86)$ & (9.15) & (9.24) \\
\hline \multirow[t]{2}{*}{ Cash Treatment at 6 months } & 7.18 & 6.30 & -1.36 & -2.75 & 16.11 & 5.90 & -0.18 & -8.42 \\
\hline & (9.86) & (9.16) & $(17.27)$ & $(10.34)$ & $(17.21)$ & $(20.45)$ & $(10.32)$ & $(10.91)$ \\
\hline \multirow[t]{2}{*}{ Cash Treatment at 9 months } & 12.97 & 5.99 & 9.60 & 3.74 & 12.64 & 11.01 & 2.37 & -0.30 \\
\hline & $(12.23)$ & $(10.96)$ & $(15.97)$ & $(11.07)$ & $(20.12)$ & $(21.36)$ & $(12.47)$ & $(11.93)$ \\
\hline \multirow[t]{2}{*}{ Cash Treatment at 12 months } & $38.09 * * *$ & $27.98 * *$ & 17.73 & 17.01 & $57.54 * * *$ & 30.41 & 10.01 & 8.82 \\
\hline & $(13.55)$ & $(12.81)$ & $(23.52)$ & $(13.42)$ & $(20.87)$ & $(25.94)$ & $(16.15)$ & $(14.69)$ \\
\hline \multirow[t]{2}{*}{ In-kind Treatment at 3 months } & $26.37 * *$ & $26.65 * *$ & $30.20 * *$ & $18.86 *$ & 33.59 & 25.34 & $22.25^{*}$ & 14.81 \\
\hline & $(12.10)$ & $(11.42)$ & $(12.64)$ & $(11.36)$ & $(22.86)$ & $(24.82)$ & $(11.89)$ & $(10.06)$ \\
\hline \multirow[t]{2}{*}{ In-kind Treatment at 6 months } & $34.62 * * *$ & $32.61 * * *$ & $38.34 * * *$ & $25.49 * *$ & 19.12 & 9.98 & $41.03 * * *$ & $35.16 * * *$ \\
\hline & $(11.68)$ & (11.19) & $(12.75)$ & $(10.93)$ & $(15.11)$ & (18.99) & $(15.44)$ & $(13.10)$ \\
\hline In-kind Treatment at 9 months & $48.33 * *$ & $48.90 * *$ & $54.91 * * *$ & $45.24 * *$ & $39.49 * *$ & $36.59 *$ & $54.76^{*}$ & $50.66^{*}$ \\
\hline \multirow[t]{2}{*}{ In-kind Treatment at 12 months } & $58.35 * * *$ & $46.91 * * *$ & $78.17^{* * *}$ & $58.00 * * *$ & $69.76^{*}$ & $75.71 * *$ & $32.76^{*}$ & $47.10^{* * *}$ \\
\hline & $(19.42)$ & $(17.52)$ & $(19.23)$ & $(17.02)$ & $(35.62)$ & $(36.58)$ & $(17.47)$ & $(15.33)$ \\
\hline \multirow[t]{2}{*}{ Constant } & $119.70 * * *$ & $102.20 * * *$ & $120.34 * * *$ & $103.05^{* * *}$ & $127.88 * * *$ & $128.69 * * *$ & $86.43 * * *$ & $87.33^{* * *}$ \\
\hline & $(8.85)$ & $(4.40)$ & $(7.38)$ & (3.71) & $(7.52)$ & $(6.47)$ & $(5.40)$ & $(4.49)$ \\
\hline Baseline trimming & No & Yes & No & Yes & Yes & Yes & Yes & Yes \\
\hline Number of Observations & 4354 & 4203 & 4354 & 4203 & 1599 & 1599 & 2604 & 2604 \\
\hline Number of Firms & 792 & 764 & 792 & 764 & 290 & 290 & 474 & 474 \\
\hline \multicolumn{9}{|l|}{ P-value for testing constant effect: } \\
\hline of Cash Treatments & 0.166 & 0.435 & 0.262 & 0.389 & 0.170 & 0.534 & 0.579 & 0.353 \\
\hline of In-kind Treatments & 0.492 & 0.577 & 0.121 & 0.163 & 0.458 & 0.249 & 0.189 & 0.057 \\
\hline
\end{tabular}

Notes:

All estimation includes wave effects. Standard errors in parentheses, clustered at the firm level.

$*, * *$ and $* * *$ denote significant at the $10 \%, 5 \%$ and $1 \%$ levels.

Trimmed specifications trim out matched quadruplets which have at least one firm with profits above 1500 cedis per month in wave 1 or 2.

OLS estimation includes dummies for the matched quadruplets. 